\title{
Franz Macbilek
}

\section{Frömmigkeitsformen des spätmittelalterlichen Adels am Beispiel Frankens}

Der Reden- und Lieddichter Lupold Homburg aus Rothenburg ob der Tauber rühmt in seiner Totenklage auf den 1347 im Zuge seiner Fehde mit den Bischöfen von Bamberg und Würzburg sowie mit den Burggrafen von Nürnberg um die Geleitstraße durch den Fränkischen Jura bei der Belagerung der Burg Neideck von einem Schleuderstein tödlich getroffenen Konrad II. von Schlüsselberg, den letzten seines Geschlechts, als einen Gotteskämpen, der bis zuletzt gegen die Ungerechtigkeit gestritten habe. Lupold Homburg bittet den Allerhöchsten, daß der Kriegsruf des Ritters „Ey Sluzzelnberg“ auch unter den Seelen im Himmel fortlebe, wo er den Schlüsselberger, nachdem ihm der himmlische Adler den ewigen Sold geschenkt habe, in der Schar der vom hl. Georg angeführten Ritter wissen will'

\author{
Abkürzungen \\ AnzGNM = Anzeiger des Germanischen Nationalmuseums \\ ARG = Archiv für Reformationsgeschichte \\ AUfr = Archiv des historischen Vereines von Unterfranken und Aschaffenburg \\ BHVB $=$ Bericht des historischen Vereins für die Pflege der Geschichte des ehemaligen Fürst- \\ bistums Bamberg \\ BJbVK $=$ Bayerisches Jahrbuch für Volkskunde \\ DI $=$ Deutsche Inschriften \\ EKGB = Einzelarbeiten aus der Kirchengeschichte Bayerns \\ FMSt $=$ Frühmittelalterliche Studien \\ HVB $=$ Historischer Verein Bamberg \\ $\mathrm{HZ}=$ Historische Zeitschrift \\ $\mathrm{JbMfr}=$ Jahrbuch des historischen Vereins für Mittelfranken \\ JFLF $=$ Jahrbuch für fränkische Landesforschung \\ RH $=$ Revue historique \\ SBAW.PH = Sitzungsberichte der Bayerischen Akademie der Wissenschaften. Philosophisch- \\ Historische Klasse \\ SÖAW.PH = Sitzungsberichte der Österreichischen Akademie der Wissenschaften. Philoso- \\ phisch-Historische Klasse \\ VGFG $=$ Veröffentlichungen der Gesellschaft für fränkische Geschichte \\ $\mathrm{VuF}=$ Vorträge und Forschungen \\ WDGB $=$ Würzburger Diözesangeschichtsblātter \\ ZBKG = Zeitschrift für bayerische Kirchengeschichte \\ $\mathrm{ZHF}=$ Zeitschrift für historische Forschung \\ ZRG KA = Zeitschrift für Rechtsgeschichte. Kanonistische Abteilung \\ 1 Clair Hayden Bell, Erwin G. Gudde, The Poems of Lupold Hornburg (Univ. of California Publ.
}


Die Ehrenrede auf den gefallenen Parteigänger Kaiser Ludwigs des Bayern macht in eindrucksvoller Weise den hohen Stellenwert deutlich, der dem Waffendienst beim Kampf für das Recht im Leben des christlichen Ritters nach Auffassung der Zeitgenossen zukam. Ganz allgemein galt der Einsatz für das Recht des Schwächeren über den Bereich des Rittertums hinaus als eines der Grundelemente adliger Ethik und adligen Frömmigkeitsverständnisses schlechthin. In der zeitgemäßen Form der Rede maß Lupold Hornburg die tapfer-fromme Lebensführung des Schlüsselbergers an dem in der Zeit der Kreuzzüge ausgeformten Leitbild des christlichen Ritters; in diese Richtung weist insbesondere auch der Wunsch, ihn in die Ritterschaft des hl. Georg aufgenommen zu wissen, dessen Gestalt den miles christianus nach damaliger Auffassung in idealer Weise verkörperte ${ }^{2}$. Trotz den sich seit der zweiten Hälfte des 12.Jahrhunderts abzeichnenden Säkularisierungstendenzen innerhalb der Adelskultur ${ }^{3}$ blieben die grundsätzlichen ethisch-religiösen Auffassungen auch in den folgenden Jahrhunderten weithin lebendig und wurden, worauf noch einzugehen ist, im Spätmittelalter in einzelnen Lebensbereichen neu belebt.

Über die allgemeinen Aussagen des Lobgedichts Lupold Hornburgs hinaus lāßt sich die fromme Einstellung des letzten Schlüsselbergers an der Förderung von Kirchen und Klöstern seines Einflußbereichs im einzelnen konkret ablesen. In besonderer Weise nahm er sich des um 1280 durch Eberhard V. von Schlüsselberg (†1283) als Haus- und Grabkloster der Familie gestifteten Zisterzienserinnenklosters Schlüsselau im Tal der Reichen Ebrach an, um dessen weitere Ausstattung sich auch Eberhards

\section{Fortsetzung Fußnote von Seite 157}

in Modern Philology 27/4, Berkeley/Los Angeles 1945) 249-251; Michel Hofmann, Ein Nachruf aus dem 14.Jahrhundert, in: Altfränkische Bilder 66 (1967) 8. - Gustav Voit, Ein Nachruf auf Konrad von Schlüsselberg, in: Fränkische Schweiz 1981, Nr. 2, 236-239; ders., Die Schlüsselberger. Geschichte eines fränkischen Adelsgeschlechtes (Nürnberg 1988) 89-91, zu Konrad II. ebd. 68-99. - Zu Lupold Hornburg zuletzt Frieder Schanze, in: Verfasserlexikon ${ }^{2}$ IV (Berlin/New York 1983) 143-146; Karl Borchardt, Die geistlichen Institutionen in der Reichsstadt Rothenburg ob der Tauber und dem zugehörigen Landgebiet von den Anfängen bis zur Reformation (VGFG IX, 34, Neustadt a. d. Aisch 1988) 124, 446, 663.

2 Zum miles christianus allgemein: Alexander von Reitzenstein, Rittertum und Ritterschaft (Bilder aus deutscher Vergangenheit 32, München 1972) 124f.; Joachim Bumke, Höfische Kultur. Literatur und Gesellschaft im hohen Mittelalter, Bd. 2 (München 1986) 399-409; Josef Fleckenstein. Das Rittertum der Stauferzeit, in: Die Zeit der Staufer. Geschichte - Kunst - Kultur. Katalog der Ausstellung, Bd. 3 (Stuttgart 1977) 103-109, hier 105f.; Roger Sablonier, Rittertum, Adel und Kriegswesen im Spätmittelalter, in: Das ritterliche Turnier im Mittelalter. Beiträge zu einer vergleichenden Formen- und Verhaltensgeschichte des Rittertums, hrsg. v. Josef Fleckenstein (Göttingen 1986) 532-570, hier bes. 556-558. - Zum Adelsethos: Hatto Kallfelz, Das Standesethos des Adels im 10. und 11.Jahrhundert (Würzburg 1960); Klaus Schreiner, „De nobilitate“. Begriff, Ethos und Selbstverständnis des Adels im Spiegel spätmittelalterlicher Adelstraktate (Habil. Tübingen 1970). - Zu den Wechselbeziehungen zwischen Adel und Spiritualitāt: Jean Leclercq, Nobiltà, in: Dizionario degli istituti di perfezione, Vol.6 (Rom 1980) 311-317. - Weitere Literatur zum Adel: Karl F. Werner, Adel. A. Fränkisches Reich, Imperium, Frankreich, in: Lexikon des Mittelalters I (München/Zürich 1980) 118-128. - Zum Adel in Franken am Beispiel des Obermaingebiets künftig: Klaus Rupprecht, Bedingungen und Strukturen ritterlicher Herrschaftswahrung im Obermainraum (14.-17. Jahrhundert) (Diss. Bamberg, vorauss. 1991).

3 Karl Bosl, Leitbilder und Wertvorstellungen des Adels von der Merowingerzeit bis zur Höhe der feudalen Gesellschaft (SBAW.PH 1947) H. 5, 32. 
Sohn Konrad I. († 1313) zusammen mit Konrads I. Neffen Gottfried I. († 1308) nach Kräften bemüht hatten, und die deshalb auch als Mitstifter des Klosters galten. Neben Schlüsselau bedachte Konrad II. die Zisterzienserklöster Langheim und Bronnbach, die Stifte St. Stephan und St. Gangolf in Bamberg und das Prāmonstratenserkloster Speinshart mit Zuwendungen ${ }^{4}$. Darüber hinaus setzte sich Konrad II. nachdrücklich für die seinem Schutz anbefohlenen Juden innerhalb des schlüsselbergischen Territoriums ein und nahm dafür auch eine Achterklärung des Kaiserlichen Landgerichts Nürnberg in Kaufs. Insgesamt lassen sich den Nachrichten zur Person und zum Wirken des letzten Schlüsselbergers eine Reihe von Zügen ablesen, die für die Frömmigkeitshaltung des spätmittelalterlichen Adels in Franken wie anderwärts als typisch gelten können.

Trotz der Fülle des vorhandenen Materials liegen zu den spätmittelalterlichen Erscheinungsformen der Frömmigkeit des Adels in Deutschland keine umfassenden oder regional angelegten Untersuchungen vor. Die Quellenlage läßt eine solche für Franken besonders lohnend erscheinen. In dem hier gesetzten engen Rahmen können nur einzelne Beispiele oder Aspekte angesprochen werden. Dabei sollen die Geschlechter der Hochfreien ebenso berücksichtigt werden wie die der Niederadligen auf dem Land. Ganz ausgeklammert werden die zum bürgerlichen Patriziat in den Städten aufsteigenden nobiles und die sich in ihren Kreisen ausbildenden spezifischen Frömmigkeitsphänomene ${ }^{6}$.

I.

In den letzten Jahrzehnten haben Forschungen zum Verhältnis von Adel und Reform, insbesondere Klosterreform, an Beispielen aus dem Hochmittelalter immer wieder auf die grundsätzliche Diskrepanz zwischen dem Standesprinzip des Adels und den in den Klöstern und Stiften gelebten monastischen Lebensformen hingewiesen und dabei zugleich das hohe, zumeist ausdrücklich auf Heilsversicherung zielende Interesse des Adels an den Klöstern hervorgehoben ${ }^{7}$. Charakteristisch für diese Einstellung sind die anhaltende Stiftungswilligkeit des Adels, die den Klöstern überhaupt erst die notwendigen ökonomischen Grundlagen zur Erfüllung ihres überweltlichen Stiftungs-

4 Stefan Nöth, Ager clavium. Das Cistercienserinnenkloster Schlüsselau 1280-1554 (Bamberg 1982) 14 ff.; Voit, Die Schlüsselberger (wie Anm. 1) $68 \mathrm{ff}$.

5 Voit, Die Schlüsselberger, 85 f., 92.

6 Hanns Hubert Hofmann, Nobiles Norimbergenses, in: ZBLG 28 (1965) 119-150. - Zu Frömmigkeitsformen Nürnberger Patrizier demnächst: Corine Schleif, Donatio et Memoria. Stifter, Stiftungen und Motivationen an Beispielen aus der Lorenzkirche in Nürnberg (München 1990).

' Hier ist vor allem auf Arbeiten von Hermann Jakobs, Josef Semmler und Joachim Wollasch hinzuweisen. Zusammentassend: Klaus Scbreiner, Mönchsein in der Adelsgesellschaft des hohen und späten Mittelalters. Klösterliche Gemeinschaftsbildung zwischen spiritueller Selbstbehauptung und sozialer Anpassung, in: HZ 248 (1989) 557-620; auch separat erschienen: Schriften des Historischen Kollegs, Vorträge 20 (München 1989); im folgenden wird nach der letzteren Publikation zitiert. 
zweckes ermöglichte ${ }^{8}$ und himmlischen Lohn für den Stifter erwarten ließ ${ }^{9}$, das Bemühen der Adligen um die Teilhabe an den Gebeten, Almosen und Messen der Klostergemeinschaften ${ }^{10}$, die Sicherung der mit Gebetsverpflichtungen der Konvente verbundenen Stiftermemoria ${ }^{11}$, die fortwährende Obsorge um den Klosterbau, um Stiftergrab und Stiftermesse im Rahmen der cura fundatorum durch die Nachfahren der Stifter ${ }^{12}$, die Umwandlung adliger Stammburgen in Hausklöster ihrer Familien ${ }^{13}$, die Konversionsbereitschaft, die zahlreiche Söhne aus dem Adel dazu bewog, den Waffendienst aufzugeben und sich dem Gesetz der klösterlichen fraternitas unterzuordnen $^{14}$, der Wunsch adliger Töchter, ihrem Leben durch den Eintritt in ein Kloster oder durch die Verbindung mit einem solchen einen über die Standesethik hinausreichenden religiösen Sinn zu geben ${ }^{15}$, die Entscheidung für die bedingungslose Nachfolge des armen und nackten Christus durch Übernahme von untergeordneten oder dienenden Funktionen innerhalb der Klostergemeinschaften ${ }^{16}$ sowie der hāufige Eintritt des Stifters, der Stifterin oder ganzer Stifterfamilien in ihre Haus- und Grabklöster am Ende ihres Lebens in der professio in extremis ${ }^{17}$. Gegenüber dem Verhältnis des Adels zu den Reformklöstern ist jenes zu den Niederkirchen bisher vorrangig aus

Schreiner, Mönchsein (wie vorige Anm.) 13.

9 Ulrike Bergmann, Prior omnibus autor. An höchster Stelle aber steht der Stifter, in: Omamenta ecclesiae. Kunst und Künstler der Romanik, hrsg. v. Anton Legner, Bd. 1 (Köln 1985) 117-148, hier bes. $119 \mathrm{f}$.; Jörg Kastner, Historiae fundationum monasteriorum. Frühformen monastischer Institutionsgeschichtsschreibung im Mittelalter (München 1974) 77-88; Franz Macbilek, Stiftergedächtnis und Klosterbau in der Chronik des Heinrich von Saar, in: In Tal und Einsamkeit. 725 Jahre Kloster Fürstenfeld, Bd. 3: Kolloquium, hrsg. v. Klaus Wollenberg (Fürstenfeldbruck 1990) 184-208, hier 195f. - Der erhoffte Lohn wird häufig in den Arengen der Adelsurkunden angesprochen; vgl. z. B. Karl Weller, Geschichte des Hauses Hohenlohe, T. II (Stuttgart 1908) 344. Zum Begriff des Stifters und des Stiftens: Otto Meyer, Die Klostergründungen in Bayern und ihre Quellen vornehmlich im Hochmittelalter, in: ZRG KA 20 (1931) 120-201, hier 183ff., 197; Gerl Zimmermann, Ebrach und seine Stifter. Die fränkischen Zisterzen und der Adel, in: Mainfränkisches Jahrbuch 21 (1969) 162-182, hier 176f., 182; Macbilek, Stiftergedāchtnis, $191 \mathrm{ff}$.

${ }_{10}$ Joachim Wollasch, Gemeinschaftsbewußtsein und soziale Leistungen im Mittelalter, in: FMSt 9 (1975) 268-286, hier u. a. 281; Dietrich Poeck, Laienbegräbnisse in Cluny, in: FMSt 15 (1981) 68-179, hier 175; Gert Althoff, Adels- und Königsfamilien im Spiegel ihrer Memorialüberlieferung. Studien zum Totengedenken der Billunger und Ottonen (München 1984).

"Zu diesem Zentralbegriff neben der in der vorigen Anm. genannten Literatur insbesondere: Karl Schmid, Joachim Wollasch (Hrsg.), Memoria. Der geschichtliche Zeugniswert des liturgischen Gedenkens im Mittelalter (Münsteraner Frühmittelalterschriften 48, München 1984).

12 Machilek, Stiftergedāchtnis (wie Anm.9).

13 Wilhelm Störmer, Die Hausklöster der Wittelsbacher, in: Wittelsbach und Bayern, Bd. I, 1, hrsg. v. Hubert Glaser (München 1980) 139-150; Schreiner, Mönchsein (wie Anm.7) 16.

14 Herbert Grundmann, Adelsbekehrungen im Mittelalter. Conversi et nutriti im Kloster, in: Ders., Ausgewählte Aufsätze, T.1 (Stuttgart 1976) 125-149; Joachim Wollasch, Parenté noble et monachisme réformateur. Observations sur les, conversions' à la vie monastique aux $\mathrm{XI}^{\mathrm{e}}$ et $\mathrm{XII}^{\mathrm{c}}$ siècles, in: RH 264 (1984) 3-24; Schreiner, Mönchsein (wie Anm.7) 13, 15.

is Schreiner, Mönchsein, $15 \%$.

16 Ebd. 16.

17 Wolfgang Brückner, Sterben im Mönchsgewand. Zum Funktionswandel einer Totenkleidsitte, in: Kontakte und Grenzen. Probleme der Volks-, Kultur- und Sozialforschung. Festschrift für Gerhard Heilfurth zum 60. Geburtstag (Göttingen 1969) 259-277; Scbreiner, Mönchsein, 14. 
lokaler Sicht bzw. aus der Sicht einzelner Adelsfamilien und verhältnismäßig selten unter umfassenden Gesichtspunkten betrachtet worden ${ }^{18}$.

Der aus Impulsen der Reformbewegung und der Idee der Pilgerfahrt zu den Stātten des ursprünglichen Christentums gespeiste Kreuzzugsgedanke fand in den Kreisen des Adels von Anfang an breite Zustimmung. Die Bereitschaft zum besonderen Einsatz für die Kirche verband sich mit der Idee des Heiligen Krieges, des Ritterkampfes im Dienst der Kirche zur Befreiung der heiligen Stätten im Heiligen Land ${ }^{19}$. HeiligKreuz- und Heilig-Grab-Verehrung wurden unter Mitwirkung adliger Heilig-LandPilger intensiviert ${ }^{20}$. Für die Mitglieder der neuen Ritterorden der Johanniter, Templer und Deutschherren verband sich der Waffendienst mit der Betreuung verwundeter, kranker und bedürftiger Heilig-Land-Pilger ${ }^{21}$. Der nach 1080 als Hospitalbruderschaft begründete Johanniterorden hat den Heidenkampf erst gut ein halbes Jahrhundert nach seinem Entstehen in sein Programm aufgenommen. In allen drei Ritterorden lebten die Mitglieder in klösterlicher Lebensform zusammen. Die unter ihnen verwirklichte Idee der militia Christi wirkte sich auch auf die ritterliche Laienfrömmigkeit aus, speziell in der Sorge um die Gründung von Spitälern. Neben der Jerusalem-Idee fand der Gedanke der Pilgerfahrt zu den Gräbern der Apostel und Heiligen im Abendland - insbesondere die peregrinatio zum Grab des hl. Jacobus in Compostela - in Kreisen des Adels großen Anklang ${ }^{22}$. Der zu den frühen Zeugnissen der peregrinatio ad limina beati Jacobi aus dem frānkischen Raum zählende Bericht über eine Fegfeuervision des Heinrich von Ahorn, eines Ministerialen des Bamberger Bischofs Otto des Heiligen und Bruders Bischof Burchards II. von Worms, aus der Zeit

${ }^{18}$ Für Franken besonders wichtig sind daher die Angaben bei: Erich Frbr. v. Guttenberg, Alfred Wendeborst, Das Bistum Bamberg (Germania Sacra II, 1, Berlin 1966) 28f., 32, 35-38; Alfred Wendeborst, Das Würzburger Landkapitel Coburg zur Zeit der Reformation (Veröff. d. MaxPlanck-Instituts f. Gesch. 13, Göttingen 1964) 14f.; Klaws Guth, Kirche und Religion, in: Oberfranken im Spätmittelalter und zu Beginn der Neuzeit, hrsg. v. Elisabeth Roth (Bayreuth 1979) 131-203, hier 141.

19 Dieter R. Bauer, Heiligkeit des Landes: ein Beispiel für die Prägekraft der Volksreligiosität, in: Volksreligion im hohen und spāten Mittelalter, hrsg. v. Peter Dinzelbacher u. Dieter R. Bauer (Paderborn u.a. 1990) 41-55; Carl Erdmann, Die Entstehung des Kreuzzugsgedankens (Stuttgart 1935, Ndr. Darmstadt 1980); Werner Goez, Wandlungen des Kreuzzugsgedankens im Hoch- und Spātmittelalter, in: Das Heilige Land im Mittelalter. Begegnungsraum zwischen Orient und Okzident, hrsg. v. Wolfdietrich Fischer u. Jürgen Scbneider (Neustadt a. d. Aisch 1982) 33-44.

${ }^{20}$ Karl Hausberger, Benno Hubensteiner, Bayerische Kirchengeschichte (München 1985) $137 \mathrm{f}$.

${ }^{21}$ Adam Wienand (Hrsg.), Der Johanniter-Orden. Der Malteser-Orden (Köln 1970); Jonatban Riley-Smith, The Knights of St. John in Jerusalem and Cyprus c. 1050-1310 (London 1967); ders., Johanniter, in: Lexikon des Mittelalters 5 (München/Zürich 1990) 613-615. - Johanniter in Franken: Borchardt, Die geistlichen Institutionen (wie Anm. 1) 117-121 u. o.; Alfred Wendeborst, Das Juliusspital in Würzburg. Bd. 1: Kulturgeschichte (Würzburg 1976) 8f. - Gerhard Rechter, Dieter Weiß, Die Ballei Franken, in: 800 Jahre Deutscher Orden. Ausstellungskatalog des Germanischen Nationalmuseums, hrsg. v. Gerbard Bott u. Udo Arnold (München 1990) 507-512.

${ }^{22}$ Luis Vázquez de Parga, José María Lacarra, Juan Uría Ríu, Las peregrinaciones a Santiago de Compostela, 3 Bde. (Madrid 1948-1949); Robert Plötz, Santiago-peregrinatio und Jacobuskult mit besonderer Berücksichtigung des deutschen Frankenlandes, in: Spanische Forschungen der Görresgesellschaft (Gesammelte Aufsătze zur deutschen Kulturgeschichte Spaniens 31, Münster 1984) 25-135; ders., Deutsche Pilger nach Santiago de Compostela bis zur Neuzeit, in: Deutsche Jakobspilger und ihre Berichte, hrsg. v. Klaus Herbers (Tübingen 1988) 1-28, hier besonders 1-5. 
um 1130 gibt zugleich einen lebendigen Einblick in die Adelsfrömmigkeit jener Zeit überhaupt und soll daher hier als Beispiel genannt werden ${ }^{23}$. Weil Heinrich von Ahorn eine zum Grab des Apostels Jacobus gelobte Pilgerfahrt aus Trägheit aufgeschoben hatte, wurde er mit Krankheit bestraft und unfreiwillig in das Purgatorium geführt, wo ihm neben anderen Bekannten Adalbero von Volsbach begegnete; Adalbero bat Heinrich, sich bei seiner Gemahlin dafür einzusetzen, ihn durch Almosen und Messen aus der Pein des Fegfeuers zu befreien. Im Fegfeuer stand Heinrich nach dem Visionsbericht dem hl. Jacobus hilfreich als Führer zur Seite. Auf Grund der Vision beeilte sich Heinrich von Ahorn, nach seiner Gesundung sofort die gelobte Pilgerfahrt nach Compostela anzutreten. Unter anderem belegt der Bericht durch die Nennung eines Nikolausaltares in der Stammburg der Ahorn im Ailsbachtal in der Fränkischen Schweiz, daß der hl. Nikolaus auch in Franken wie anderwārts zu den frühen Adelsheiligen zählte ${ }^{24}$.

Die Tatsache, daß sich die drei fränkischen Domkapitel von Würzburg, Eichstātt und Bamberg mit wenigen Ausnahmen aus nachgeborenen Söhnen des fränkischen Adels rekrutierten, der auch in vielen Stiften, Männer- und Frauenklöstern das Adelsprinzip durchsetzte, hatte zur Folge, daß neben den allgemeinen Erwartungen und Wertmaßstäben des Adels auch die spezifisch adligen Frömmigkeitsformen in jenen Institutionen mehr oder weniger Platz griffen, und daß umgekehrt die religiösen Vorstellungen auf dem Weg über die Familien in die adlige Laienfrömmigkeit übernommen wurden ${ }^{25}$.

23 Elias t: Steinmeyer, Eduard Sievers (Hrsg.), Die althochdeutschen Glossen, Bd.4 (Berlin 1898) 491-493.

24 Michel Hofmann, Heinrich von Ahorn im Fegfeuer (um 1130). Ein fränkischer Nachtrag zum Dante-Gedenkjahr 1965, in: JFLF 26 (1966) 199-215; Plötz, Santiago-peregrinatio (wie Anm. 22) 95; ders., Deutsche Pilger (wie Anm. 22) $16 \mathrm{f}$. - Zur Nikolausverehrung allgemein: Gerd Zimmermann, Patrozinienwahl und Frömmigkeitswandel im Mittelalter, dargestellt an Beispielen aus dem alten Bistum Würzburg, in: WDGB 20 (1958) 24-126; 21 (1959) 5-124, hier Bd. 21, 29 f.

${ }^{25} \mathrm{Zu}$ den grundsătzlichen Fragen, insbesondere auch zum Adelsprinzip, jetzt: Scbreiner, Mönchsein (wie Anm. 7). Auf die hier $43 \mathrm{ff}$. angesprochene, sich im Lauf des Spätmittelalters ständig beschleunigende Entwicklung vieler Klöster zu Versorgungsanstalten des Adels und den damit verbundenen negativen Auswirkungen auf das Ordensleben kann im vorliegenden Zusammenhang nicht eingegangen werden. Einige allgemeine Hinweise - auch auf einschlägige Literatur - bei Gïnter Dippold. Die fränkischen Zisterzen und ihr Verhältnis zu den Landesherren, in: In Tal und Einsamkeit, Bd. 3 (wie Anm. 9) hier 100 mit Anm.348. - Zur Problematik des Adelsprinzips ausführlich: Alfred Wendeborst, Der Adel und die Benediktinerklöster im späten Mittelalter, in: Consuetudines monasticae. Eine Festgabe für Kassius Hallinger aus Anlaß seines 70. Geburtstages, hrsg. v. Joachim F. Angerer u. Josef Lenzenweger (Rom 1982) 333-353. - Zur Entwicklung in einzelnen Klöstern und Stiften: Dieter Michael Feineis, Die Herrschaft des Ritterstiftes St. Burkard in Waldbüttelbrunn (Forschungen zur Fränkischen Kirchen- u. Theologiegeschichte 4, Würzburg 1978); August Leidel, Geschichte der Benediktinerabtei Wülzburg (Mittelfränkische Studien 4, Ansbach 1983) bes.413-417; Rainer Jooß, Kloster Komburg im Mittelalter (Forschungen aus Württ. Franken 4, Schwäbisch Hall 1971, gek. Sigmaringen ${ }^{2} 1987$ ); Luduig Unger, Die Reform des Benediktinerklosters St. Michael bei Bamberg in der 2. Hälfte des 15. Jahrhunderts (HVB Beiheft 20, Bamberg 1987); IJeinz Pfublmann, Spenn, zwytrecht, gebrechen und widerwillen. Zwei Schiedsverträge des Bamberger Bischofs Heinrich III. Groß von Trockau zwischen Abt und Konvent des Klosters Banz von 1488 und 1490, in: Geschichte am Obermain 16 (1987/88) 49-65. 
II.

Die zuvor skizzierten Einstellungen und Frömmigkeitsformen des Adels im Hochmittelalter lebten zum größeren Teil im Spātmittelalter fort.

Uber die bei Stiftungen des Adels wirksamen Intentionen geben gelegentlich die Arengen der Fundationsurkunden Aufschluß. Als Beispiel läßt sich der Stiftungsbrief der Euphemia von Taufers, der Witwe des Andreas von Hohenlohe-Brauneck anführen, mit welchem diese 1324 die einst als Morgengabe an sie gelangte Burg Lichtel südlich von Creglingen samt dem gleichnamigen Dorf und dem Kirchensatz dem Deutschen Orden zur Errichtung einer Kommende schenkte. In der Arenga heißt es: "Wie die irdischen Burgen und Festen, die zu Raubhäusern gemacht und gestiftet werden, wovon Unfriede und Ungemach in der Christenheit ausgehen, ein Vorbau und Vorwerk des höllischen Kerkers und eine Festung des ewigen Todes sind, so sind die irdischen Burgen und Festen, die dem Gottesdienst einverleibt werden, in denen Gottesdienst gedeiht und von denen aus Friede und Gnade in der heiligen Christenheit erblüht, ein Vorbau und Vorwerk der ewigen Himmelsfeste und eine Sicherheit des Lebens, das mit unsäglicher Freude ohne Ende wāhrt." ${ }^{26}$ Inwieweit die Betrachtung als Äußerung der Gesinnung der Ausstellerin anzusehen ist und „offenbar einem ganz persönlichen Uberzeugtsein “ der Stifterin Ausdruck gibt, wie Karl Weller annahm $^{27}$, oder auf den Diktator des Stückes zurückgeht, läßt sich nicht entscheiden ${ }^{28}$.

Unter den Stiftungen von Ordensniederlassungen von seiten des fränkischen Adels ragen die für die Ritterorden und für die Kartäuser besonders hervor. Eine wichtige Rolle spielten in diesem Zusammenhang die Hohenlohe: 1192 stiftete Albrecht von Hohenlohe im Zusammenwirken mit Friedrich Barbarossa die Johanniterkommende Reichardsroth, 1208 folgte die Stiftung der Johanniterkommende Mergentheim durch Albrecht. 1219 stifteten die drei in den Deutschen Orden eingetretenen Brüder Andreas, Heinrich und Friedrich von Hohenlohe die Deutschordenskommende Mergentheim $^{29}$. Wie sich die Hohenlohe persönlich für lange Zeit mit Mergentheim verbanden, so die Zollern mit der Kommende Virnsberg; beide können als Hauskommenden der genannten Familien angesprochen werden ${ }^{30}$. Die Errichtung der Kommende Virnsberg war 1294 durch Burggraf Konrad II. von Nürnberg und seine Gemahlin Agnes, eine Tochter Albrechts von Hohenlohe, erfolgt. Zusammen mit sei-

26 Zitiert bei Weller, Geschichte II (wie Anm. 9) 343, $430 \mathrm{f}$. - Die Motive der Stiftung des Zisterzienserinnenklosters Sonnefeld bei Coburg durch Heinrich II. von Sonnefeld (1260 ff.) aus den Urkunden zusammengestellt bei Walter Lorenz, Campus solis. Geschichte und Besitz der ehemaligen Zisterzienserinnenabtei Sonnefeld bei Coburg (Schriften d. Inst. f. Fränkische Landesforschung an der Univ. Erlangen-Nürnberg, Histor. Reihe 6, Kallmünz 1955) 65, $71 \mathrm{f}$.

${ }_{27}$ Geschichte II (wie Anm. 9) 343.

${ }^{28}$ Zur Bedeutung der Arengen in spātmittelalterlichen Privaturkunden allgemein: Ingo Reiffenstein, Deutschsprachige Arengen des 13. Jahrhunderts, in: Festschrift für Max Spindler zum 75. Geburtstag, hrsg. von Dieter Albrecht, Andreas Kraus, Kurt Reindel (München 1969) 177-192.

29 Weller, Geschichte II (wie Anm.9) 343; Borcbardt, Die geistlichen Institutionen (wie Anm. 1) 19.

${ }^{30}$ Gerbard Rechter, Dieter J. Weiß, Die Ballei Franken, in: Kat. 800 Jahre Deutscher Orden (wie Anm. 21) 507-512, hier 507. 
nem Bruder Friedrich trat Konrad II. selbst in die Virnsberger Kommende ein. Er wurde später wegen seiner Stiftungen an mehrere geistliche Institutionen „der Fromme" genannt ${ }^{31}$.

Graf Poppo II. von Wertheim dotierte um 1210/20 die Deutschordenskommende Eschenbach (Wolframseschenbach), Graf Otto von Botenlauben 1240 die Deutschordenskommende Münnerstadt. Durch Stiftungen von seiten der Grafen von Hirschberg und umsitzender Dienstadliger stieg das seit 1180 durch die Edelfreien von Ellingen gestiftete Armenspital zu Ellingen um 1250/53 zu einer der wichtigsten Kommenden des Deutschen Ordens in Franken auf ${ }^{32}$. Aus Stiftungen der Brüder Gebhard, Kraft und Konrad von Krautheim an die Johanniterniederlassung in Wölchingen von 1287 erwuchs die Johanniterkommende Boxberg ${ }^{33}$.

Die Johanniter und Deutschherrenniederlassungen in Franken, darunter auch die nicht von Adligen gestifteten, erlebten im 13. Jahrhundert einen steilen Aufstieg vor allem auf Grund von Zuwendungen aus Kreisen des niederen Adels ${ }^{34}$.

Auffallend ist der relativ hohe Anteil der Adelsstiftungen bei den fränkischen Kartausen: Immerhin die Hälfte verdankte ihre Existenz seinem Stiftungseifer. Die Nova Cella zu Grünau im Spessart wurde 1328 durch Elisabeth von Wertheim dotiert ${ }^{35}$. Erkinger von Seinsheim, der Stammvater des Fürstenhauses Schwarzenberg, gründete 1409 die Kartause Marienbrück gegenüber Volkach am Main als Begräbnisstätte für seine Familie ${ }^{36}$. 1453 errichteten der Ritter Balthasar Fere von Berg und seine Frau Magdalena von Vestenberg an der Stelle ihrer Burg zu Ilmbach im westlichen Steigerwald die Kartause Mariengarten ${ }^{37}$. Der bei der Favorisierung der Kartäuser offenbar im Vordergrund stehende Gedanke des stellvertretenden Gebets wird bei der Gründung von Marienbrück als Familiengrablege besonders deutlich.

Ernst Schubert hat an Beispielen aus Thüringen darauf hingewiesen, daß die fundatores in den Klöstern eine geradezu heiligenähnliche Stellung einnahmen. Die Stiftergrabsteine der Thüringer Landgrafen in Reinhardsbrunn bildeten nach Schubert "eine Art Andachtsbilder für die zur Grabstätte des, heiligen' Ludwig und jener beiden anderen Ludowinger wallfahrenden Gläubigen, die vor allem von Landgraf Ludwig IV. Fürsprache und Heilung erhofften und dem Kloster mit ihren Spenden erheblichen

31 Weller, Geschichte II (wie Anm. 9) 206 f.; Gerhard Rechter, Das Land zwischen Aisch und Rezat. Die Kommende Virnsberg Deutschen Ordens und die Rittergüter im Oberen Zenngrund (Neustadt a. d. Aisch 1981) $29 \mathrm{f}$.

32 Borchardt, Die geistlichen Institutionen (wie Anm. 1) 19; Dieter J. Wiiß. Die Deutschordenskommende Ellingen, in: ZBKG 59 (1990) 3-21, hier 4-6.

${ }_{33}$ Borchardt, Die geistlichen Institutionen (wie Anm. 1) 118.

${ }^{34}$ Ebd. 118; Weiß (wie Anm. 32) 6.

35 Norbert Backmund, Die kleineren Orden in Bayern und ihre Klöster bis zur Säkularisation (Windberg 1974) 64f.; Karl Peter Bültner, Die unterfränkischen Kartausen, in: Kartäusermystik und -mystiker, Bd. 2 (Analecta Cartusiana 55, Salzburg 1981) 56-82, hier 58; James Hogg. The Charterhouse of Grünau, ebd. 192-204, hier 192. - Die Kartause erfuhr durch die Rieneck, Rüd und Bickenbach besondere Förderung: Büttner, 59; Hogg, 193.

36 Backmund, Die kleineren Orden (wie vorige Anm.) 59 f.; Büttner, Die unterfränkischen Kartausen (wie vorige Anm.) $62 \mathrm{f}$. $-\mathrm{Zu}$ adligen Stiftungen: Michael Wieland. Die Karthause Ostheim und ihre Bewohner, in: AUfr 38 (1896) 1-35, hier $32 \mathrm{f}$.

${ }^{37}$ Backmund, Die kleineren Orden (wie Anm.35) 65f.; Bütther (wie Anm.35) $64 \mathrm{f}$. 
Nutzen brachten“. Nach Schubert wurden Grabmäler dieser Art „zum Zwecke liturgischer Feiern ante effigiem für jene Toten in Auftrag gegeben“" ${ }^{\text {"38. }}$.

Vergleichbare Funktionen sind auch für die zahlreichen erhaltenen oder durch $\mathrm{Ab}$ bildungen bzw. Beschreibungen überlieferten Denkmāler adliger Stifter in frānkischen Klöstern anzunehmen, wie sie vielfach in den Chören der Klosterkirchen, gelegentlich auch in eigenen Grabkapellen in der Nähe der Chöre Aufstellung fanden. Erinnert sei hier nur an die Denkmäler adliger Stifter in Ebrach, Langheim oder Theres ${ }^{39}$. In allen drei KJöstern wurde das Gedāchtnis im 15. bzw. 16. Jahrhundert durch neue Denkmäler oder die Anbringung von Gedenktafeln mit Gedenktexten neu belebt, wohl in der Absicht, die das Kloster aufsuchenden Adligen religiös zu motivieren und sie zugleich zu Spenden an das Kloser zu ermuntern. In allen drei Fällen waren die adligen Fundatoren nicht die alleinigen Klosterstifter, wurden aber in besonderer Weise hervorgehoben. In Ebrach hielten drei Gedenktafeln aus dem Ende des 15. Jahrhunderts die Verdienste Richwins, Bernos und der Berthildis mit folgenden Versen fest:

„Richwin ein ritter streng hie $z w$ eberach gesessen sich ewigen lon $\mathrm{zw}$ erobern vleissig vermessen

Ein schwarzen greiffen er gefürdt hat

Diss closter alls erster stiffter wolbegnadt.“

„Berno ein pruder richwini was

Mit im erster stiffter $z w$ Eberach saß

gut vnd hab er sich vm gott erwach

Im geistligem leben er verzert sein tach."

„Berthildis aus dem Geschlecht deren von Ebrau

Ihren Erbteil auch gab zu des Klosters Bau.

Verhofft dadurch zu erlangen das ewige Leben,

Welches ihr Gott der Allmächtig wolle geben." ${ }^{\text {40 }}$

Die zahlreichen Spitalgründungen des fränkischen Adels sind ideell im Zusammenhang mit den Spitalgründungen der geistlichen Ritterorden zu sehen. Sowohl Hochadlige als vereinzelt auch Ritter folgten im späten Mittelalter diesem Beispiel. Die adligen Spitalgründungen erfolgten zeitlich in der Periode, in der die aktive Spitalpflege der Ritterorden zurücktrat und die Spitalgründungen in den Reichsstädten und bür-

38 Drei Grabmāler des Thüringer Landgrafenhauses aus dem Kloster Reinhardsbrunn, in: Skulptur des Mittelalters. Funktion und Gestalt, hrsg. v. Friedrich Möbius u. Ernst Scbubert (Weimar 1987) 211-242, hier 215, 221 f.; Macbilek, Stiftergedächtnis (wie Anm.9) $195 \mathrm{f}$.

39 Die Inschriften des Landkreises Bamberg bis 1650 , hrsg. v. Rudolf $M$. Kloos in Zusammenarbeit mit Lothar Bauer u. mit Beiträgen v. Isolde Maierböfer (DI 18, München 1980) Nrn. 20, 101, 102, 103; Günter Dippold, Non verus et proprius monasterii fundator. Otto und Kloster Langheim, in: BHVB 185 (1989) 339-358, hier 339 ff., 349; Die Inschriften des Landkreises Haßberge, bearb. v. Isolde Maierböfer (DI 17, München 1979) Nr.1+.

40 DI 18 (wie vorige Anm.), - Zu den Stiftertraditionen im Benediktinerkloster Münchaurach: Gerhard Pfeiffer, Die Gründung des Klosters Münchaurach, in: WDGB 26 (1964) 18-41, hier bes. $28-40$. 
gerlichen Spitalgründungen in den Landstādten sowie die landesherrlichen Spitäler zunahmen. Neben den religiösen Intentionen standen wie bei den bürgerlichen Spitalgründungen Motive der Repräsentation und des Familiengedāchtnisses sichtbar im Vordergrund, doch sind hier wie dort wirtschaftliche Interessen unverkennbar.

Nach bisheriger Kenntis ist die Gründung eines Siechenspitals durch Elisabeth von Wertheim, die Witwe Gottfrieds von Hohenlohe, um 1315 zu Neubrunn die zeitlich früheste Spitalstiftung von seiten des Adels in Franken. Elisabeth stand mit dem in Neubrunn ansāssigen Deutschen Orden in enger Verbindung. Das Spital wurde schon 1319 nach Stadtprozelten verlegt ${ }^{41}$. 1352/53 stiftete Burkard von Seckendorff-Jochsberg das Spital zu Gunzenhausen ${ }^{42}, 1357$ Gottfried III. von Hohenlohe-Brauneck das Spital zu Aub bei Ochsenfurt, zu dessen weiteren Wohltätern die ortsansässigen Truchseß von Baldersheim zählten ${ }^{43} .1360$ stifteten Gerlach von Hohenlohe und seine Frau Margareta, eine Tochter Ludwigs des Bayern, das Spital zu Uffenheim. Mitglieder der Familie der Truchseß von Baldersheim dotierten 1412/22 das Spital zu Röttingen, dessen Vorgängerinstitution offensichtlich in Schwierigkeiten geraten war ${ }^{44}$.

In den sechziger Jahren des 15.Jahrhunderts ist eine Häufung adliger Spitalgründungen festzustellen: 1462 zu Weismain als Stiftung des dort ansāssigen Heinz von Giech zum Gedächtnis an seine Frau, seine Tochter und ein Mädchen, die beim vorausgehenden Stadtbrand ihr Leben verloren hatten ${ }^{45}$, 1462/63 zu Kronach als Stiftung des Georg von Zeyern, des damaligen bambergischen Amtsmanns zu Waldenfels und seiner Frau Anna ${ }^{46}, 1464$ zu Feuchtwangen als Stiftung des dort amtierenden markgräflich brandenburg-ansbachischen Amtmanns Adam von Kirchberg ${ }^{47}$.

Außerordentlich hoch war der Anteil des fränkischen Adels an den Pfarreigründungen des 12. bis 15.Jahrhunderts. Die Zahl der von seiten der besitzkräftigen hochfreien Geschlechter, der Ministerialen bzw. des niederen Adels im Gebiet des Bistums

41 Bayerisches Städtebuch, T. 1 [Franken], hrsg. v. Erich Keqser u. Heinz Stoob (Deutsches Städtebuch V/1, Stuttgart usw. 1971) 538.

42 Rechter, Das Land (wie Anm. 31) 180, 88; ders., Ein niederadeliger Territorialpolitiker im spätmittelalterlichen Franken: Burkard von Seckendorff-Jochsberg, in: JbMfr. 95 (1990/91) 19-32.

43 Jobann Kübles, Beitrāge zur Geschichte des Spitales in Aub, in: AUfr 21/1-II (1871) 39-80, hier 41; Alfred Wendehorst, Das Juliusspital in Würzburg, Bd.I: Kulturgeschichte (Würzburg 1976).

44 Bayer. Städtebuch 1 (wie Anm. 41) 554. - Wendehorst, Das Juliusspital (wie Anm. 43) 12

45 Heinz von Giech übertrug die Brandstätte an die Stadt mit dem Auftrag, dort „zu hilf den liben selen und ir leib, do selbst schaden entpfangen hat, zu eyner erquickunge und aufhaldunge der durftigen und armen menschen, zu eyner capelln, zu eyner behausunge eynes spitals [...], darinnen dan itzmals sechs person armer durtiger menschen nach vermogen erquickt ernert werden". Marlene Besold-Backmund, Stiftungen und Stiftungswirklichkeit. Studien zur Sozialgeschichte der beiden oberfränkischen Kleinstädte Forchheim und Weismain (Schriften des Zentralinstituts f. Frānkische Landeskunde u. allgemeine Regionalforschung an der Univ. Erlangen-Nürnberg 27, Neustadt a. d. Aisch 1986) 77.

${ }_{46}$ Georg Hummel, Das Bürger-Spital zu Kronach, seine Entstehung und ältere Geschichte (Kronach o.J.); Bayerisches Städtebuch 1 (wie Anm. 41) 341.

47 Bayerisches Städtebuch 1 (wie Anm. 41) 201. - Daneben gab es zahllose Zustiftungen an bereits bestehende Spitäler aus adligen Familien. Vielfach behielten sich diese bei Pfründenstiftungen das Recht auf die Besetzung der Pfründen vor; dazu z. B. Besold-Backmund, Stiftungen (wie Anm. 45) 77. 
Bamberg errichteten Pfarreien übertraf jene von seiten der Bischöfe, Stifte und Klöster im genannten Zeitraum bei weitem ${ }^{48}$. Für das 12. und 13. Jahrhundert stehen danach 19 quellenmäßig belegbaren bzw. wahrscheinlichen Pfarreigründungen von Bischöfen, Stiften und Klöstern 37 belegbare bzw. wahrscheinliche Gründungen von Hochfreien, Ministerialen bzw. Niederadligen gegenüber, darunter 27 Gründungen von Hochfreien und 10 Gründungen des niederen Adels. Im 14. und 15. Jahrhundert stehen 23 belegbaren bzw. wahrscheinlichen Gründungen von Bischöfen, Stiften und Klöstern 37 Gründungen von Hochfreien und Niederadligen gegenüber, darunter 8 Gründungen von Edelfreien und 29 von Angehörigen des niederen Adels. Die Umkehrung der Zahlen der Pfarreigründungen von seiten der edelfreien Geschlechter und des niederen Adels in der zweiten Phase gegenüber der ersten ist die natürliche Folge des fast völligen Erlöschens der hochfreien Familien im Raum des Bistums Bamberg im Lauf des 13. Jahrhunderts. Um 1200 erloschen die als Hauptvögte der Bamberger Kirche fungierenden Grafen von Abenberg-Frensdorf, 1248 die seit der Mitte des 12.Jahrhunderts von den Bamberger Bischöfen mit dem Grafenamt im Radenzgau belehnten Andechser, seit 1180 Herzöge von Meranien, 1271 die Ahorn, um 1300 die Walpoten, 1308 die Hauptlinie der Schlüsselberg. Im gleichen Zeitraum erfolgte der Aufstieg der Ministerialen des Bischofs, der Stifte und Klöster und der bedeutendsten Laienherren zum ritterbürtigen niederen Adel, aus dem im 15.Jahrhundert die reichsunmittelbare Ritterschaft erwuchs. Der mit dem 14.Jahrhundert einsetzende Anteil einzelner Stadtbürger an den Pfarreigründungen blieb gering. Dagegen übertrafen die Kommunen im 15.Jahrhundert mit 15 Pfarreigründungen den niederen Adel um ein Fünftel. Insgesamt verdankte somit im Bistum Bamberg nahezu die Hālfte aller zwischen 1100 und 1500 errichteten Pfarreien ihre Gründung dem Adel. Auch im Gebiet der Bistümer Würzburg und Eichstätt wurden die Pfarreien vorwiegend durch hochfreie und ministeriale bzw. ritterliche Geschlechter dotiert ${ }^{49}$. Uber die Patronatsrechte, die der Adel weitgehend in seiner Hand behielt, wahrte er sich einen wichtigen Einfluß auf das kirchliche Geschehen, vor allem in den Landpfarreien; entsprechend fanden hier auch zahlreiche Ausdrucksformen der Adelsfrömmigkeit einen vielfach bis heute sichtbaren Niederschlag.

Der Bereich der frommen Stiftungen des fränkischen Adels läßt sich in seiner Vielfalt hier auch in groben Zügen nicht befriedigend überschauen. $\mathrm{Zu}$ nennen sind neben der Dotierung von Burgkapellen, Altären, Messen samt den dazugehörigen Pfründen und Ausstattungen insbesondere die Errichtung der Erbbegräbnisse vornehmlich in Stifts-, Kloster- oder Stadtkirchen. Die 1352 durch den Ritter Wolfram von Rotenhan gestiftete Vikarie am Bartholomäusaltar der Bamberger Domkirche war mit der Sepultur des Geschlechtes im Kapitelhaus am Dom verbunden; zahlreiche Zustiftungen, darunter die Dotation eines Jahrtags, belegen das Interesse der Familie an den Verbindungen zur Domkirche. Eine Reihe ihrer Mitglieder erlangte hier Kanonikate;

${ }^{48}$ Hierzu und zum Folgenden: Guttenberg/Wendeborst (wie Anm. 18).

49 Alfred Wendeborst, Franken, Landschaft, in: Lexikon des Mittelalters Bd.4 728-735. Ders., Das Landkapitel Coburg (wie Anm. 18). - Zu dem fast völligen Erlöschen der Schicht der hochfreien Herren im Bereich des Bistums Bamberg seit dem 13. Jahrhundert: Erich Frhr. v. Guttenberg, Die Territorienbildung am Obermain, in: BHVB 79 (1927) 1-539, hier 296-298. 
1431 wurde der Bamberger Domherr Anton von Rotenhan Bischof von Bamberg $(\dagger 1459)^{50}$.

Bei allen Adelsstiftungen wird die memoria der Familie besonders betont. Die auf den gestifteten Altāren, Altargerāten und Ornaten angebrachten Wappen oder die zahlreichen Darstellungen der Stifter und ihrer Familien auf den Predellen machten diese Absicht für die Nachfahren der Stifter sichtbar und bewahrten durch sie gekennzeichnete Stücke später gelegentlich vor Vernichtung ${ }^{31}$. Beispiele dafür sind das Relief der vor einer Kreuzigungsgruppe knienden Stifter Georg und Anna von Zeyern an der äußeren Chorstirnwand der Spitalkirche zu Kronach sowie das Relief des vor einem Schweißtuch der Veronika knienden Georg von Zeyern über seinem Wappen an der Chorrückwand im Innern der Kapelle, der 1465 durch den Ritter Hans von Wallenrode zum Gedächtnis an seine Frau Sibylle von Lentersheim ( 1454$)$ gestiftete Katharinenaltar in der Pfarrkirche zu Schwabach mit den Wappen der Eheleute auf der Predella $^{52}$ und der 1487 von Ludwig V. von Eyb für seine verstorbene Frau Magdalena Adelmann von Adelmannsfelden $(† 1472)$ in die Heidecker Kapelle zu Heilsbronn gestiftete Martins- und Ambrosiusaltar mit einer Darstellung der Familie des Stifters; die Männer tragen ritterliche Rüstung, zum Teil mit darüber gelegtem Mantel, die Frauen kostbare Roben. Ludwig von Eyb und sein Sohn Anselm sind mit den Insignien des Schwanenritterordens ausgezeichnet ${ }^{53}$.

so Gottfried Frbr. v. Rotenban, Die Rotenhan. Genealugie einer frānkischen Familie von 1229 bis zum Dreißigjährigen Krieg (VGFG IX/34, Neustadt a. d. Aisch 1985). - Für das 15. Jahrhundert auch Jobannes Kist, Die Matrikel der Geistlichkeit des Bistums Bamberg 1400-1556 (VGFG IV/7, Würzburg 1965) $336 \mathrm{f}$ - Beispiele für Familien- und Erbbegräbnisse: Theodor Ruf, Die Grafen von Rieneck. Genealogie und Territorienbildung. II. Herkunftstheorien und Systematik der Territorienbildung (Mainfränkische Studien 32/II, Würzburg 1984) 203-207. - Wilhelm Engel, Urkundenregesten zur Geschichte der kirchlichen Verwaltung der Grafschaft Wertheim 12761499 (Wertheim 1959) Nr. 138 f. - Dietrich Deeg, Die Herrschaft der Herren von Heideck. Eine Studie zu hochadliger Familien- und Besitzgeschichte (Freie Schriftenfolge der Gesellschaft für Familienforschung in Franken 18, Neustadt a. d. Aisch 1968) 71 f. - Italo Bacigalupo, Der Gutenstettener Altar. Ein Werk der Nümberger Meister Hans Peheim und Veit Wirsberger (Ars Bavarica 45/46, München 1987) 149-151 (Grablege der Aufseß in der St. Kilianskapelle zu Kloster Langheim). - Gerbard Rechter, „difficulteten und beschwerden“. Beobachtungen zum Verhältnis der kleineren Reichsstädte Frankens zum niederen Adel am Beispiel Windsheim, in: Reichsstädte in Franken. Aufsätze, hrsg. v. Rainer A. Müller (München 1987) 298-308, hier 301; Heinrich Geiling, Die Geiling, ein fränkisches Rittergeschlecht (Bibliothek familiengeschichtlicher Arbeiten 44, Neustadt a. d. Aisch 1982) 17 (im Augustiner-Eremitenkloster zu Windsheim). Alfred Heidacher, Entstehung und Wirtschaftsgeschichte des Klosters Heilsbronn bis zum Ende des 15. Jahrhunderts (Bonn 1955) 20 f. (Grablege der Vestenberg in der Ritterkapelle des Zisterzienserklosters Heilsbronn).

si Helmut Hundsbichler, Gerhard Jaritz, Elisabeth Vavra. Tradition? Stagnation? Innovation? Die Bedeutung des Adels für die mittelalterliche Sachkultur (Veröffentlichungen des Instituts für mittelalterliche Realienkunde Österreichs 5, Wien 1982) 35-72, hier bes. 49-53.

52 Alfred Stange, Kritisches Verzeichnis der deutschen Tafelbilder vor Dürer, III. Bd. Franken, bearb. v. Peter Strieder u. Hanna Härtle (München 1978) Nr. 75.

${ }_{53}$ Ebd. Nr. 204; Eberhard Frbr. $v$ : Eyb, Das reichsritterliche Geschlecht der Freiherren von Eyb (VGFG IX/29, Neustadt a. d. Aisch 1984) 101, 107. - Reliefs des Spitalstifters, eines Ritters von Zeyern: 650 Jahre Friesen. Die Geschichte einer Frankenwaldgemeinde (Kronach 1978) 18. Auf den 1975 in der Sakristei der Pfarrkirche zu Kirchlauter unweit von Haßfurt entdeckten 
Über die Ausstattung der vom Adel gestifteten oder ihm auf Grund des Patronatsrechtes nahestehenden Pfarrkirchen und Kapellen mit Vasa sacra, Büchern und Ornaten geben neben Stiftungsurkunden und Testamenten vor allem Nekrologe und Jahrtagsverzeichnisse sowie die in Franken zahlreich überlieferten, bisher nur vereinzelt ausgewerteten Pfarrbücher Aufschluß. Als Beispiel der zuletzt genannten Gattung eignet sich das 1498 angelegte Gültbuch der Pfarrkirche zu Lehrberg bei Ansbach, das über die zahlreichen Stiftungen der Birkenfelser, einer ursprünglich zum Dornberger Dienstadel gehörigen, im 15.Jahrhundert im Ort zugezogenen Familie, Aufschluß gibt. Genannt werden im einzelnen die Stiftung eines ewigen Lichtes vor dem Liebfrauenaltar der Kirche, das jeweils durch den Senior des Geschlechts der Birkenfelser während der heiligen Ämter am Brennen erhalten werden soll, zwei durch Ursula von Birkenfels, eine geborene Crailsheim, gestiftete Jahrtage sowie eine durch Hans von Birkenfels, seine Frau Ursula und ihre Kinder Wilhelm und Elisabeth errichtete Salve Regina-Stiftung, außerdem verschiedene Altargerāte, „altargezierd“ und Ornate ${ }^{\text {s4. }}$. Hāufig waren die Adelsstiftungen mit Sonderzuweisungen an die Konventualen oder Insassen der beschenkten Klöster bzw. Spitäler, mit der Spendung von Almosen an bedürftige Arme oder der Gewährung von Präsenzgeldern an die bei den gestifteten Gottesdiensten mitwirkenden Geistlichen und Laien verbunden ${ }^{55}$.

\section{Fortsetzung Fußnote von Seite 168}

Fresken hält das Wappen der Flieger von Bischofsheim/Zeil die Erinnerung an die Stifterfamilie fest: Norbert Kandler, Ritterschaft, Dienstadel und Lehensherren in den Haßbergen, in: WDGB 52 (1990) 223-242, hier 235. - Der um die Mitte des 15. Jahrhunderts errichtete Chor der Pfarrkirche zu Seidmannsdorf bei Coburg trägt Schlußsteine mit den Wappen der Brandenstein und Waldenfels als Hinweise auf deren Beitrag zum Kirchenbau: Armin Leistner, Wappenführende Geschlechter im Coburger Land, in: Jahrbuch der Coburger Landesstiftung 35 (1990) 1-76, hier 9.

54 Staatsarchiv Nürnberg, Fst. Brandenburg-Ansbach, Salbücher Nr.66. Das Buch ist auf der Titelseite selbst als Gültbiich der pfarrkirchen zu Lerperg bezeichnet. Zur Familie der Birkenfels: Rechter, Das Land (wie Anm. 31) 141 ff. - Günter Dippold erwähnt in seiner ungedruckten Bamberger Diplomarbeit, Das kirchliche und geistige Leben in Staffelstein vom späten 15. zum frühen 17. Jahrhundert (1987), aus dem Staffelsteiner Pfarrbuch von 1504, das im Pfarrarchiv Staffelstein aufbewahrt wird, eine Seelbadstiftung des in Weismain ansässigen Kaspar von Pünzendorf († 1486): 6 Arme sollen vom Ertrag der gestifteten $26 \mathrm{fl}$ kostenlos zu bestimmten Zeiten „baden und kopfen" (47).

ss Stiftungen von Pitanzen und Reichnissen durch adlige Familien für den Konvent der Zisterzienserinnen von Mariaburghausen und für die Klosterkapläne: Rainer Wailersbacher, 750 Jahre Kloster Kreuzthal-Mariaburghausen (Vallis Sanctae Crucis) 1237/43-1582 (Haßfurt 1987) 94, 74. - Prāsenzgelder: Engel, Urkundenregesten (wie Anm. 50) Nr. 138 f. - Klaus Frbr. v. Andrian-Werburg verweist am Beispiel des Franziskanernekrologs aus Coburg darauf, wie vielfältig die Anlässe wie auch die Art der Gaben in diesen Zusammenhängen waren: Das Totenbuch des Franziskanerklosters in Coburg ca. 1257-1525 (1600), bearb. v. K. Frbr. v. A.-W. (VGFG IV/10, Neustadt a. d. Aisch 1990) $12^{\circ} \mathrm{f}$. 
III.

Die Patrozinienwahl in den durch den fränkischen Adel begründeten Pfarrkirchen und Kapellen, insbesondere den Burgkapellen, entspricht im wesentlichen dem aus anderen Landschaften des Reiches bekannten Bild. Bevorzugte Standespatrone sind neben Michael und Martin vor allem Mauritius, Georg, Sebastian, Pancratius, Leonhard sowie die Heiligen Drei Könige. Die seit den Kreuzzügen durch den Adel geförderte Kreuzverehrung lāßt sich in Franken an einer Reihe von Heilig-Kreuz-Kapellen ablesen, so an der Burgkapelle zu Cadolzburg oder an der Kapelle des Burggutes zu Neunkirchen am Sand, die der hl. Helena und dem hl. Kreuz geweiht war ${ }^{36}$. Eine wichtige Rolle als Beschützer von Burgkapellen spielte auch der hl. Nikolaus, der jedoch ein bei allen Ständen beliebter Heiliger war. Auf das in der Fegfeuervision des Heinrich von Ahorn belegte Nikolauspatrozinium der Kapelle der Burg Ahorn im Ailsbachtal wurde bereits hingewiesen ${ }^{57}$. Neben den genannten männlichen Adelsheiligen wurden seit dem 12.Jahrhundert die drei Jungfrauen und Martyrinnen Margareta, Katharina und Barbara, seit dem 13. Jahrhundert die hl. Elisabeth besonders verehrt. Hoch über der Verehrung spezieller ritterlicher Heiliger stand im Adel die Verehrung Marias, wobei ihre Herkunft aus dem Stamm des Königs David besonders betont wurde. An Quellenmaterial aus dem alten Bistum Würzburg hat Gerd Zimmermann in seiner Untersuchung über Patrozinienwahl und Frömmigkeitswandel im Mittelalter exemplarisch dargelegt, in welch hohem Maß der frānkische Adel die Verehrung der Ritterheiligen in seinen Stiftungen, nicht zuletzt in den Burgkapellen, heimisch gemacht hat ${ }^{58}$. Zu den Kapellen in den Burgen der Frānkischen Schweiz finden sich in den Burgenbüchern des 1980 verstorbenen Arztes und Burgenforschers Hellmut Kunstmann wertvolle Hinweise ${ }^{59}$.

Bei den ritterlichen Heiligen anvertrauten Pfarrkirchen an Adelssitzen ist im Einzelfall zu prüfen, ob das Patrozinium tatsächlich das ursprüngliche ist oder ob ältere biblische oder fränkische Heilige als Patrone vorausgingen. So löste das Patrozinium des hl. Mauritius in Königshofen an der Tauber das des hl. Martin ab. Das Mauritiuspatrozinium dürfte die Kirche der adligen Patronatsherrschaft der Grafen von Riencck verdanken; da der Zeitpunkt des Patrozinienwechsels unbekannt ist, muß offen bleiben, ob Mauritius hier noch als Königsheiliger oder bereits als Ritterheiliger anzusprechen ist ${ }^{60}$.

s6 Zimmermann, Patrozinienwahl (wie Anm. 24) Bd. 21, 94. Wilbelm Schwemmer. Neunkirchen am Sand. Aus der Vergangenheit einer Gemeinde im Rothenberger Land (Altnürnberger Landschaft, Mitteilungen 27, Sonderheft, Nürnberg 1978) $21 \mathrm{f}$.

57 Zum Nikolauspatrozinium bei staufischen Pfalzkapellen und der Kapelle eines Ministerialensitzes aus staufischer Zeit: Fritz Arens, Staufische Pfalz- und Burgkapellen, in: Die Burgen im deutschen Sprachraum. Ihre rechts- und verfassungsgeschichtliche Bedeutung, Bd.I, hrsg. v. Hans Patze (VuF XIX, Sigmaringen 1976) 197-210, hier 209f. - Dazu auch oben Anm. 24.

s8 Zimmermann, Patrozinienwahl (wie Anm. 24) Bd. 21, 38-60.

50 Sein 1967 in Würzburg erstmals erschienenes Buch Mensch und Burg. Burgenkundliche Betrachtungen an ostfrānkischen Wehranlagen (VGFG IX/25) enthält 75-78 einen zusammenfassenden Abschnitt über die Burgkapellen (Neustadt a. d. Aisch ${ }^{2} 1985$ ).

${ }^{60}$ Zimmermann, Patrozinienwahl (wie Anm. 24) Bd.21, 45 f. - Das Margareta-Patrozinium der 
Der in der spātmittelalterlichen Frömmigkeit allgemein zu beobachtenden Tendenz zur Kumulation entsprechend wurden die Burgkapellen vielfach dem Schutz mehrerer Ritterheiliger zugleich anvertraut. So war z.B. die 1339 durch Burkard von Seckendorff gestiftete Burgkapelle zu Jochsberg unweit Ansbach Maria, Petrus, Georg, Burkard, dem Namenspatron des Stifters, Elisabeth und Margareta geweiht ${ }^{61}$. Mehrfach wurden den in Adelskreisen beliebten Titeln oder Heiligen die Patrone der jeweiligen Diözese zur Seite gestellt wie im Fall der 1344 durch Wolfram von Rotenhan und seine Frau Lukardis in die Burgkapelle zu Rentweinsdorf im Itzgrund gestifteten Vikarie, die neben dem Schutz des Heiligen Kreuzes jenem der hl. Kunigunde und des hl. Pancratius unterstellt war ${ }^{62}$. Als Grafentochter und Königin bzw. Kaiserin stand Kunigunde dem Adel ohnedies nahe ${ }^{63}$.

Die hl. Elisabeth erfreute sich seit der Erhebung ihrer Gebeine und Krönung ihres Hauptes durch Kaiser Friedrich II. 1236 ständig steigender Beliebtheit und Verehrung unter dem Adel ${ }^{64}$. Graf Ludwig von Öttingen übergab $1318 \mathrm{zu}$ ihren Ehren und zu ihrem Gedächtnis dem Dekan und Kapitel des Stifts St. Gumbert zu Ansbach einen jährlichen Zins von $1 \mathrm{lb}$ hl.; ihr Fest soll dafür in der Stiftskirche jeweils mit neun Lektionen und ihrer Historia nach Gewohnheit des Stifts begangen werden ${ }^{65}$. Als besondere Verehrerin der hl. Landgräfin erwies sich die Gräfin Elisabeth von Wertheim († 1335), die durch ihre Schenkungen an den Deutschen Orden ,geradezu eine Nachahmerin ihrer Namenspatronin“ war ${ }^{66}$. Der Nachweis auf die Abstammung von der hl. Elisabeth in der Ahnenprobe auf dem von Tilman Riemenschneider geschaffenen Grabmal der Gräfin Dorothea von Wertheim, einer geborenen Gräfin von Rieneck

\section{Fortsetzung Fußnote von Seite 170}

seit dem 14.Jahrhundert als Pfarrkirche belegten Kirche zu Lehrberg bei Ansbach, einer ursprünglichen Eigenkirche des Stifts Herrieden, wird bereits anläßlich einer Weihe durch Bischof Gundekar von Eichstātt im Jahr 1059 genannt. In der zweiten Hälfte des 15.Jahrhunderts entwickelte sich zwischen der in Lehrberg zugezogenen, ursprünglich dem Dombergischen Dienstadel zugehörigen Familie der Birkenfels (wie oben Anm. 54) und der Pfarrkirche eine enge Verbindung, für die das vorgegebene Patrozinium durchaus förderlich gewesen sein dürfte.

6t Paul Schöffel, Der Archidiakonat Rangau am Ausgang des Mittelalters, in: JFLF 5 (1939) 132175, hier 157.

62 Rotenhan, Die Rotenhan (wie Anm. 50) 11, 32.

63 Zimmermann, Patrozinienwahl (wie Anm. 24) Bd. 21, 80. - Zur Kunigundenverehrung allgemein: Renate Klauser, Der Heinrichs- und Kunigundenkult im mittelalterlichen Bistum Bamberg, in: BHVB 95 (1965) 1-209; Elisabeth Roth, Sankt Kunigunde - Legende - Bildaussage, in: BHVB 123 (1987) 5-68.

64 Dabei wirkten offensichtlich ritterliche Frömmigkeitsvorstellungen mit den Idealen der Armutsbewegung zusammen: Zimmermann, Patrozinienwahl (wie Anm. 24) Bd. 21, 56, 79. - Zu allgemeinen Fragen der Elisabethverehrung: Helmut Beumann, Friedrich II. und die heilige Elisabeth. Zum Besuch des Kaisers in Marburg am 1. Mai 1236, in: Sankt Elisabeth. Fürstin Dienerin - Heilige (Sigmaringen 1981) 151-166; Udo Arnold, Georg und Elisabeth - Deutschordensheilige als Pfarrpatrone in Preußen, in: Die Rolle der Ritterorden in der Christianisierung und Kolonisierung des Ostseegebietes, hrsg. v. Zenon Hubert Nowak (Ordines militares. Colloquia Torunensia historica 1, Thorn 1983) 69-78.

65 Urkunden und Regesten des Klosters und Stiftes St. Gumbert in Ansbach 786-1400, bearb. v. Walter Scherzer (VGFG III/5, Neustadt a. d. Aisch 1989) Nr.124.

${ }_{66}$ Hermann Ebmer, Die Ahnenprobe der Gräfin Dorothea von Wertheim geb. von Rieneck auf ihrem Grabmal in Grünsfeld, in: Mainfränkisches Jahrbuch 41 (1989) 169-182, hier 179. 
(† 1503), in der Stadtkirche zu Grünsfeld bei Tauberbischofsheim wird neuerdings als zeitgemāße „Herausforderung an das gräfliche Haus Wertheim“ gewertet, „ebenfalls den hohen Adel seiner Vorfahren zu belegen ${ }^{\text {} 67}$.

\section{IV.}

Die Burgkapellen bestanden auf den Hochburgen aus Platzmangel vielfach nur aus einem einzigen engen Raum. Bei zahlreichen Burgen befanden sich die Kapellen außerhalb der Hauptburg im Vorhof oder am Fuß des Berges, so u. a. bei den Burgen Wallenrode, Egloffstein, der aufsessischen Burg Freienfels, bei den Burgen Leutenbuch oder Rabeneck ${ }^{68}$. Bei der Stammburg des aus dem ehemaligen andechs-meranischen Ministerialengeschlecht der Blassenberg erwachsenen Geschlechts der Herren von Guttenberg im Frankenwald bestand im Vorhof der seit 1315 errichteten Hochburg eine Marienkapelle, die anläßlich der Errichtung einer Kaplanei 1352 erstmals urkundlich erwähnt wird, und die nach der Zerstörung durch einen Kriegshaufen des Schwäbischen Bundesheeres 1523 aufgegeben wurde, sowie am Fuß des Berges eine anläßlich ihrer Weihe 1379 erstmals erwähnte Fronleichnamskapelle, in welche damals das knapp drei Jahrzehnte zuvor errichtete Benefizium aus der Marienkapelle übertragen wurde. 1442 wurde die Fronleichsnamskapelle von der Pfarrei Untersteinach abgetrennt und unter guttenbergischeın Patronat zur selbstāndigen Pfarrkirche erhoben ${ }^{69}$.

Die Notizen über die Weihe der Fronleichnamskapelle im Jahr 1379 zählen zu den selten überlieferten Weihenachrichten von Burgkapellen ${ }^{70}$. Danach hatte die neue Kapelle drei Altäre. Der Hochaltar wurde zu Ehren des Fronleichnams sowie der hll. Petrus und Paulus, Maria, Vinzenz, Nikolaus, Otto, Kunigunde, Dorothea und Helena geweiht, der rechte Seitenaltar zu Ehren der hll. Georg, Andreas, Thomas, Oswald,

${ }^{67}$ Ebd. 179. - Zur Geschichte der Grafen von Wertheim allgemein: Hermann Ehmer, Geschichte der Grafschaft Wertheim (Wertheim 1989).

${ }^{68}$ Kunstmann. Mensch und Burg (wie Anm. 59) $77 \mathrm{f}$. - Auf Burg Rieneck gab es zwei Kapellen: eine kleine im Bergfried sowie eine große im Hof: Arens, Staufische Pfalz- und Burgkapellen (wic Anm. 57) 208.

69 Guttenberg/Wendehorst, Das Bistum Bamberg (wie Anm. 18) $211 \mathrm{f}$; Hellmut Kunstmann, Schloß Guttenberg und die früheren oberfränkischen Burgen des Geschlechts (VGFG IX/22, Würzburg 1966) 42.

70 W'ilhelm Erhard (Hrsg.), 600 Jahre Evang. Kirche St. Georg Guttenberg. Kath. Schloßkirche 200 Jahre. Festschrift und Ausstellungskatalog (Guttenberg 1979) 47; Wilhelm Deinhardt (Hrsg.), Dedicationes Bambergenses. Weihenotizen und -urkunden aus dem mittelalterlichen Bistum Bamberg (Freiburg i. Br. 1936) Nr. 73. - Auch für die 1357 durch den Bamberger Ministerialen Wolfram II. von Redwitz und seinen Sohn Iring VI. gestiftete Burgkapelle zu Theisenort liegt eine Weihenotiz vor; danach stand in der Kapelle ein einziger Altar, den der Bamberger Weihbischof zu Ehren der hll. Andreas, Nikolaus und der hl. Katharina weihte. Den Spendern für den Unterhalt der Kapelle und den Pilgern wurden Ablässe gewährt: Deinhardt, Dedicationes Nr. 62; Gustav Voit, Der Adel am Obermain. Genealogie edler und ministerialer Geschlechter vom 11. bis 14.Jahrhundert (Die Plassenburg 28, Kulmbach 1969) 282, Anm. 78. - Zur Weihe der Kapelle auf dem Gügel bei Scheßlitz (St. Pancratius und St. Georg): Deinbardt. Dedicationes Nrn.91b und 119. 
Erasmus, Gordian und Epimachus, Anastasia und Margareta, der linke Seitenaltar zu Ehren der hll. Antonius, Bartholomāus, Cosmas und Damian, Gereon, der Elftausend Jungfrauen, Urban, Barbara und Agnes. Die in den Altären deponierten Reliquien waren wohl zunāchst vom Reliquienfundus des Konsekrators, des Weihbischofs Walter von Nicopolis, bestimmt, sie geben aber offensichtlich auch Einblick in die frommen Intentionen des Burgherrn. Eine kurz darauf von Heinrich und Fritz von Guttenberg auf den Georgsaltar gestiftete Frühmesse wurde 1383 durch den Bamberger Generalvikar bestātigt. Nach Erhebung der Kapelle zur Pfarreikirche stiftete ein Mitglied der Familie 1477 eine Liebfrauenmesse auf den Hauptaltar. Seit Beginn des 15. Jahrhunderts wurde die Fronleichnamskapelle als Grablege der Guttenberg benutzt. Zu den ersten hier bestatteten Mitgliedern des Geschlechts gehörten die beiden Stifter der Frühmesse, die 1407 und 1409 verstorben waren ${ }^{71}$.

Die Errichtung repräsentativer großer Kapellen in Burgnähe und die Erhebung von Burgkirchen zu Pfarrkirchen ist in vielen Fällen mit der Einrichtung von Grablegen verbunden. Hāufig wurde die bis dahin geübte Beisetzung der Mitglieder der Adelsfamilien in den Klöstern ganz oder zum Teil aufgegeben ${ }^{72}$.

Einblicke in das bewegliche Inventar einer Reihe von Burgkapellen am Übergang vom Mittelalter zur Neuzeit vermitteln einige der in jüngster Zeit von Rudolf Endres, Werner Goez und Eva Pleticha herangezogenen, aber noch nicht erschöpfend ausgewerteten Schadenslisten fränkischer Ritter aus dem Bauernkrieg von 1525, die im Staatsarchiv Bamberg verwahrt werden ${ }^{73}$. Die Listen zeigen, daß die Burgherren große Sorgfalt auf die würdige Ausstattung der Kapellen verwendeten und hohe Ausgaben dafür nicht gescheut haben; sie ermöglichen in einzelnen Fällen aber darüber hinaus Rückschlüsse auf ihre spezifische Frömmigkeitsausrichtung.

Rochus von Seckendorff zu Hallerndorf bei Forchheim aus der Linie der Seckendorff-Gutend stellt als Verluste aus der Kapelle fest: 3 Altartafeln, davon 1 mit vergoldetem „gemell“ und 2 mit „erhoben bilden“, also Reliefs, weiter 1 vergoldetes „deffelle“, 2 Kelche, 1 seidenes gemosiertes Meßgewand nach niederländischer Art mit goldenen Rosen samt Zubehör, 8 Altartücher, davon eines in karmesinem Atlas, ein weiteres mit Seide ausgenäht und mit einer Korporaltasche mit goldenen Knöpfen, sowie 6 alltägliche, 1 "hantzwehel“. Die bei den einzelnen Stücken angegebenen Wertansätze ergeben zusammen eine Summe von mindestens $145 \mathrm{fl}^{74}$.

Für die Burgkapelle zu Wichsenstein bei Pegnitz meldet Paulus von Planckenfels

7 Guttenberg/Wendeborst, Das Bistum Bamberg (wie Anm. 18) 212.

72 So z. B. von der Familie Guttenberg, die ihre Toten in älterer Zeit vielfach in den Klöstern Langheim und Himmelkron bestattet hatte.

${ }^{73}$ Bauernkriegsakten (Rep. 48) Nrn. 6 und 7. - Rudolf Endres, Adelige Lebensformen in Franken zur Zeit des Bauernkrieges (Neujahrsblätter der Gesellschaft für Fränkische Geschichte XXXV, Würzburg 1974); ders., Adelige Lebensformen in Franken im Spätmittelalter, in: Adelige Sachkultur des Spätmittelalters. Intern. Kongreß Krems a. d. Donau 1980 (SÖAW.PH 400, Wien 1982) 73-104; Werner Goez, Das Leben auf der Ritterburg, in: Mentalitāt und Alltag im Spätmittelalter, hrsg. v. Cord Meckseper u. Elisabetb Scbraut (Göttingen 1985) 9-33; Eva Pleticha, Adel und Buch. Studien zur Geisteswelt des fränkischen Adels am Beispiel seiner Bibliotheken vom 15. bis zum 18. Jahrhundert (VGFG IX/33, Neustadt a. d. Aisch 1983) 16f., 21, $23 \mathrm{f}$.

74 Staatsarchiv Bamberg (fortan: StAB), Rep. 48, Nr. 7, Prod.42, 6 und 4. 
folgende Schăden: den zu Ehren des hl. Laurentius geweihten Altar, „schla ich an umb 25 gulden zu weyen und zuzurichten," den Altarstein, 4 Meßgewänder, davon 1 aus Samt, 1 aus Schamlot und 2 aus Seide, 3 davon mit Kreuzen, 1 silberner, vergoldeter Kelch mit Patene, 1 weitere Patene aus Silber, mit etlichen guten Steinen und Perlen eingefaßt, 3 Korporaltaschen, darin 5 Korporale, 5 in die Kapelle gehörige Bücher, 6 Altartücher, 2 gemalte Vorhänge, 1 Tafel mit Heiltum, 1 zierlich eingefaßtes Täfelchen aus Zypressenholz, 4 Meßkandeln, 3 Glöckchen, 2 Zinnleuchter. Der Gesamtwert wird auf $120 \mathrm{fl}$. angeschlagen ${ }^{73}$.

Umfangreiche Aufstellungen insbesondere über zu Schaden gegangenes Altargerāt und über Ornate finden sich in den Schadenslisten des Gabriel von Streitberg auf Grub (Burggrub) in der westlichen Frānkischen Schweiz sowie des Wilhelm von Wiesenthau zu Peulendorf nö. Bamberg. In ersterer werden genannt: 1 Meßgewand mit einem Kreuz mit Bildwerk (Kreuz und darunter ein Bild des hl. Johannes), 1 Albe mit Zugehörungen, alles mit braunen Schilden, 3 Altartücher, 1 geweihter merbelsteinerner Altarstein, 1 großes Crucifix, darunter Maria und Johannes, 1 Vesperbild, 1 Bild der Anna Selbdritt, 1 gedrucktes neues Meßbuch, wie es von Bischof Veit herausgegeben wurde, 1 gedruckte deutsche Bibel des Alten und Neuen Testaments, „nit luterisch“, aus dem Besitz seines verstorbenen Schwagers, 1 Passional der Heiligen Leben, gedruckt und mit Figuren ausgestrichen ${ }^{76}$. Wilhelm von Wiesenthau vermerkt zu den von ihm angeführten Meßbüchern, Altargeräten und -tüchern sowie Meßornaten: „was im schloß zu Peulendorff genommen ist worden, das dem gotzhaus daselbst zusteet" ${ }^{\text {"7? }}$. Mit großer Wahrscheinlichkeit hatte Wilhelm von Wiesenthau das angeführte Gut vor den Bauern auf dem Schloß in Sicherheit gebracht.

Bei einigen Listen ist der Aufbewahrungsort der angeführten Gegenstände nicht besonders angegeben, doch dürften sie am ehesten in den Burgkapellen verwahrt gewesen sein: Wolf von Egloffstein zu Egloffstein nennt u.a. „viel heylthumbs“ und 1 ,ror vom heyligen landt", deren Wert er zusammen auf mindestens 50 Gulden schätzte, Klaus von Königsfeld zu Wattendorf eine gemalte vergoldete Tafel im Wert von 2 Gulden, Balthasar von Egloffstein 1 gemaltes Tuch, „daran dye heyligen drey kunig gemalt warden“, deren Wert er gleichfalls mit 2 Gulden anschlug ${ }^{78}$.

13 StAB, Rep. 48, Nr. 7, Prod. 49,3. - Endres, Adelige Lebensformen in Franken zur Zeit des Bauernkriegs (wie Anm. 73) $27 \mathrm{f}$; ders., Adelige Lebensformen in Franken im Spätmittelalter (wie Anm. 73) 86, 103.

76 StAB, Rep. 48, Nr.7, Prod. 44,9; Prod. 51, 12 und 15. - Pleticha, Adel und Buch (wie Anm. 73) $23 \mathrm{f}$. - Ein unter dem Bamberger Bischof Veit I. Truchseß von Pommersfelden (1501-1503) gedrucktes Missale ist bei Ferdinand Geldner, Die Bruchdruckerkunst im alten Bamberg 1458/59 bis 1519, Bamberg 1964, 76, 93, nicht angegeben. Vom sog. Prosapassional (Der Heiligen Leben) liegen über 40 Frühdrucke vor; dazu: Konrad Kunze, in: Verfasserlexikon ${ }^{2} 3$ (Berlin/New York 1981) 617-625; hier ist am ehesten an den mit zahlreichen Holzschnitten ausgestatteten Druck von Anton Koberger (Nürnberg 1488) zu denken.

77 StAB, Rep. 48, Nr. 7, Prod. 51, 12.

78 StAB, Rep.48, Nr.6, Prod. 7,22; Prod. 18; Prod.7, 1 und 2. - Endres, Adelige Lebensformen in Franken im Spätmittelalter (wie Anm.73) 86; ders., Adelige Lebensformen in Franken zur Zeit des Bauernkrieges (wie Anm. 73) 27. - Utz von Rüsenbach zu Trunstadt gab eine große lange seidene Fahne mit einem Frauenbild als Schaden an: StAB, Rep. 48, Nr.6, Prod. 37, 7 und 2. - Aus den Schadenslisten ebenso wie aus dem überkommenen Inventar wird deutlich, daß der Adel für 
Heiltümer aus dem Heiligen Land genossen beim Adel, speziell unter der Ritterschaft, stets besondere Devotion. Überhaupt lassen sich Reliquien in ritterlichem $\mathrm{Be}$ sitz relativ häufig nachweisen, wie ein um 1360 angelegtes Inventar des altbayerischen Ritters Erhard Rainer von Schambach bei Straubing und andere Aufstellungen zeigen $^{79}$. Unter den Schätzen des Schambachers befand sich wie bei Wolf von Egloffstein Heiltum aus dem Heiligen Land, nämlich eine Zierkerze vom Heiligen Grab zu Jerusalem $^{80}$. Die von dem Ritter Florian Waldauf für Hall in Tirol gesammelten Heiltümer wurden um 1500 in einem gedruckten Heiltumsbuch allgemein bekannt gemacht ${ }^{81}$. Nach dem Tod des Sebastian Nold von Seckendorff († 1495), des früheren Amtmanns zu Neustadt an der Aisch, wurde bei der Erbverhandlung festgehalten, daß das von ihm hinterlassene "heyligthumb "in der Kirche zu Neuendettelsau verbleiben soll, wo der Verstorbene und seine Eltern begraben liegen ${ }^{82}$.

Die im Adel besonders verehrten Heiligen und deren Legenden bestimmten die Programme der Ausstattungen der Adelskirchen in hohem Maß mit. Zwischen 1971 und 1977 wurde im Turmgeschoß der ehemaligen Kapelle und heutigen Pfarrkirche St. Georg zu Friesen bei Kronach ein Zyklus von 18 Darstellungen aus der Legende des Kirchenpatrons aus dem Ende des 15.Jahrhunderts freigelegt, der zu den geschlossensten Werken seiner Art im östlichen Franken zählt ${ }^{83}$. Die gelegentlich geäußerte Vermutung, daß es sich bei der erzählfrohen Darstellung um ein Werk des jungen Lukas Cranach handelt ${ }^{84}$, bedarf noch gründlicher Uberprüfung; die Fragen nach Cranachs Werk vor seiner Wittenberger Zeit sind vorerst noch völlig offen. Die einzelnen Szenen weisen weitgehende UUbereinstimmungen mit der Georgslegende des

\section{Fortsetzung Fußnote von Seite 174}

eine ausreichende und würdige Ausstattung seiner Kapellen durchaus Sorge getragen hat. Daß nur verhältnismäßig wenige Auflistungen von Kapelleninventar vorliegen, dürfte darauf beruhen, daß die wertvollen Vasa sacra und Ornate vor den anrückenden Bauern in Sicherheit gebracht wurden und daß die Bauern die Kapellen in der Regel von Plünderungen verschont haben.

79 Torsten Gebhard, Volkskundliche Untersuchungen zu dem Inventar des Ritters Erhard Rainer von Schambach bei Straubing aus der Zeit um 1360, in: BJbVK 1978/79, 61-72; hier 70, Anm. 1, Hinweise aul weitere Inventare; Leonhard Theobald, Das Heiltum- und Ablaßbuch Degenhart Pfeffingers, in: Beiträge zur bayer. Kirchengeschichte 32 (1925) 49-70.

${ }^{80}$ Gebhard, Volkskundliche Untersuchungen (wie vorige Anm.) 64.

s1 Harry Kühnel, Frömmigkeit ohne Grenzen? In: Alltag im Spätmittelalter, hrsg. v. dems. (Graz/ Wien/Köln ${ }^{2}$ 1986) 92-1 20, hier 99; Erich Egg, Stiftungen - Heiltum - Ablässe, in: Heiltum und Wallfahrt. Tiroler Landesausstellung. Prämonstratenserstift Wilten und Benediktinerabtei St. Georgenberg-Fiecht 1988 (Innsbruck 1988) 58-81, hier 69-76; Katalogbeschreibung ebd. Nrn. $1.14-19,138-145$.

${ }_{82}$ Gerbard Rechter, Die Seckendorff. Quellen und Studien zur Genealogie und Besitzgeschichte Bd. II: Die Linien Nold, Egerdorf, Hoheneck und Pfaff (VGFG IX/36, Neustadt a. d. Aisch 1990) 68; ders., Regesten der Urkundenreihen seckendorffischer Gutsarchive in Mittelfranken (Bayerische Archivinventare, Neustadt a. d. Aisch 1991) Nr.608.

83 Elisabeth Roth, Gotische Wandmalerei in Oberfranken. Zeugnis der Kunst und des Glaubens (Würzburg 1982) 55-57.

${ }_{84} 650$ Jahre Friesen (wie Anm. 51) 203-205. - Zum jungen Lukas Cranach: Rainer Hambrecht, Die Kursächsischen Rechnungsbücher im Staatsarchiv Coburg und ihr Quellenwert für die Person Lukas Cranachs d. Älteren, in: Jahrbuch der Coburger Landesstiftung 32 (1987) 53-96, hier 53. 
weitverbreiteten, 1488 bei Anton Koberger in Nümberg gedruckten Prosapassionals auf ${ }^{85}$, das sich an Hand der Schadenslisten aus dem Bauernkrieg auch im Besitz zweier Ritter nachweisen läßt ${ }^{86}$. Auftraggeber der Ausmalung, zu der noch ein Jüngstes Gericht am Chorbogen zählt, war mit großer Wahrscheinlichkeit ein Mitglied der nach Zeyern, wenige Kilometer östlich von Friesen benannten ritterlichen Familie, die in der zweiten Hälfte des 15. und zu Beginn des 16.Jahrhunderts im Kronacher Raum überörtliche Bedeutung erlangt hatte. Es ist verlockend, aber durch die Quellen nicht eindeutig zu belegen, daß der 1537 verstorbene Georg von Zeyern den Zyklus zur Ehre seines Namenspatrons anbringen ließ, der in der Familie als solcher schon von jeher in Ehren stand ${ }^{87}$. Eine Stiftung der Truchseß von Pommersfelden oder der Familie von Egloffstein ist der um 1518 entstandene sog. Altar der Hll. Ritter in der Pommersfeldener Filialkirche zu Limbach, dessen Skulpturen vom Nürnberger Marthameister und dessen Tafeln mit den heiligen Rittern Mauritius, Georg, Florian und einem vierten Ritter, möglicherweise Gereon, von Hans Süß von Kulmbach bzw. aus dessen Werkstatt stammen ${ }^{\mathbf{8 8}}$. Auch die Auswahl der Heiligen im Skulpturenprogramm entspricht den besonderen Frömmigkeitsintentionen des Adels; vertreten sind u. a. Laurentius und Leonhard. Auch die auf der Predella angebrachte Darstellung von Christus und den Aposteln ist in jener Zeit auf Kunstwerken aus dem ritterlichen Umfeld häufig; genannt sei als Beispiel nur der von Ameley von Waldau, der Witwe des Götz von Rotenhan auf Rentweinsdorf, in die Rotenhansche Sepultur beim Bamberger Dom gestiftete Apostelabschied aus der Zeit um $1500^{89}$. Nach Tilman Breuer tritt der Ritterstolz des ritterlichen Patrons beim Limbacher Altar der Truchseß von Pommersfelden besonders hervor, ,auf dessen Flügeln bei geschlossenem Schrein vier

85 S. O. 144

Bo S.u. 154.

87 Klaus J. Dorsch, Georgszyklen des Mittelalters. Ikonographische Studien zu mehrszenigen Darstellungen der Vita des heiligen Georg in der abendländischen Kunst unter Einbeziehung der Einzelszenen des Martyriums (Frankfurt a. M. 1983). - Zur Familie von Zeyern: 650 Jahre Friesen (wie Anm. 51) 16-25. Zu den erlittenen Schäden im Bauernkrieg: StAB, Rep.48, Nr.7, Prod.56, 1-5. - Zum Vergleich mit den Friesener Fresken wird auf den gut erhaltenen Georgszyklus der ehemaligen Burgkapelle der Seefelder auf dem Hohenpeißenberg bei Weilheim in Oberbayern verwiesen; dazu zuletzt: Dorolbea Greven, in: Katholischer Digest 43 (1989) Heft 9, 30-33.

88 Meister um Albrecht Dürer. Kat. der Ausstellung Nümberg Germanisches Nationalmuseum (AnzGNM 1960/61) Nr. 174; Martin Kubn. Sankt Mauritius mit der Lanze, der ottonische Reichspatron, an der Schwelle zwischen Franken und Thüringen, in: Geschichte am Obermain 7 (1971/72) 51-76, hier 65; Gude Suckale-Redlefsen unter Mitarbeit v. Roberi Suckale. Mauritius: Der heilige Mohr. The Black Saint Maurice (Related Menil Foundation Publications 3, Houston/ München/Zürich 1987) 239 mit Abb.101. - In Dietenhofen bei Ansbach befindet sich in der Pfarrkirche, deren Patronat bei den Leonrod lag, die hier auch ihre Familiengrablege hatten, ein Altarretabel aus der Zeit um 1510/20 u.a. mit einem hl. Mauritius: ebd. $239 \mathrm{f}$.

89 Renate Baumgärtel-Fleischmann unter Mitarbeit v. Bruno Neundorfer, Bernbard Schemmel u. Walter Milutzki, Die Altäre des Bamberger Doms von 1012 bis zur Gegenwart (Veröffentlichungen des Diözesanmuseums Bamberg 4, Bamberg 1987) 54-57; Rotenban, Die Rotenhan (wie Anm. 50) VIII, 185. 
ritterliche Heilige posieren, die Rüstung freilich schon mehr als elegantes Standesattribut tragend. ${ }^{\text {990 }}$

\section{V.}

Den der Fürbitte für die Toten und dem Totengedächtnis eingeräumten Rang lassen die zahllosen Jahrtagsstiftungen und einschlägigen Bestimmungen in den Testamenten sowie die trotz großer Verluste immer noch imponierende Zahl erhaltener Grabdenkmäler, Epitaphien und Totenschilde erkennen ${ }^{91}$. Vor allem dank des für Franken bereits in einigen wichtigen Bänden vorliegenden Inschriftenwerks und einer kunstgeschichtlichen Untersuchung von Günther Bräutigam über die Darstellung des Verstorbenen in der figürlichen Grabplastik Frankens und Schwabens sind für den zuletzt genannten Bereich bereits fundierte Aussagen möglich ${ }^{92}$. Sie decken sich im wesentlichen mit den von Helfried Valentinitsch am österreichischen Material für die Realienkunde getroffenen Feststellungen. Danach lassen sich die männlichen Angehörigen des niederen Adels in der Sepulkralplastik in der Regel bewaffnet und in voller Rüstung als Repräsentanten ihres Standes abbilden, wodurch die religiöse Funktion des Grabdenkmals in vielen Fällen in den Hintergrund gedrāngt wurde. Demgegenüber verlangte nach Valentinitsch das der adligen Frau abverlangte Rollenbild verstärkt die Zurschaustellung religiöser Hinwendung, so daß die auf den Grabdenkmälern dargestellten Frauen in der Regel in betender Haltung, vielfach zusätzlich mit einem Rosenkranz in den Hānden, und in üppiger, vom Haupt bis zum Boden reichender Verhüllung dem Betrachter gegenüberstehen ${ }^{93}$.

90 Tilmann Breuer, Kunstdenkmäler im Landkreis, in: Landkreis Höchstadt a. d. Aisch. Vergangenheit und Gegenwart (Aßling-München 1970) 149-160, hier 154.

91 Beispiele von Testamenten: Gustav Voit, Der Adel an der Pegnitz 1100 bis 1400 (Freie Schriftenfolge der Gesellschaft für Familienforschung in Franken 20, Neustadt a. d. Aisch 1979) 132 (1418), 272 (1424) usw.; ders., Die Schlüsselberger (wie Anm. 1) 62 f., 198 f. (1308), 54, $204 \mathrm{f}$. (1313). - Nicht immer handelte es sich um ecbte Schenkungen: Mit seinem Testament aus dem Jahre 1266 schenkte Ulrich von Dürn dem Benediktinerkloster Amorbach eine Reihe von Gütern „ad restitucionem dampnorum et multorum gravaminum, que per me meosque ipsi monasterio tam in personis quam in rebus illate recognosco eisque defensionem ac pacem debitam substrahendo". Es handelte sich nach eigener Aussage Ulrichs demnach um keine echte Schenkung, sondern eine Art Wiedergutmachung, immerhin jedoch mehr oder weniger aus frommer Gesinnung. Wilhelm Störmer, Miltenberg (Historischer Atlas von Bayern, Teil Franken 1/25, München 1979) 76.

${ }^{22}$ Günther Bräutigam, Die Darstellung des Verstorbenen in der figülichen Grabplastik Frankens und Schwabens vom Ende des 13.Jahrhunderts bis um 1430 (Diss. Masch. Erlangen 1953). - DI (vgl. oben Anm. 39) 1: Die Inschriften des badischen Main- und Taubergrundes. Wertheim - Tauberbischofsheim, bearb. v. Ernst Cucuel u. Hermann Eckert (Stuttgart 1942, Ndr. Stuttgart 1969); DI 8: Die Inschriften der Landkreise Mosbach, Buchen und Miltenberg, bearb. v. Heinrich Köllenberger (Stuttgart 1964); DI 15: Die Inschriften der Stadt Rothenburg o. d. Tauber, bearb. v. Dietrich Lutz (München 1976); DI 17: Die Inschriften des Landkreises Haßberge (wie oben Anm. 39); DI 18: Die Inschriften des Landkreises Bamberg bis 1650 (wie Anm. 39); DI 27: Die Würzburger Inschriften bis 1525 , bearb. v. Karl Borchardt (Wiesbaden 1988).

93 Helfried Valentinitsch, Die Aussage des spătmittelalterlichen Grabmals für die adelige Sach- 
Im einzelnen ist dieses Schema jedoch häufig durchbrochen: Schon früh kommen auch mānnliche Adlige mit gefalteten Händen vor, z. B. Heinrich von Seinsheim $(† 1345)$ in Mariaburghausen ${ }^{94}$. Eine große Zahl männlicher Adliger hält einen Paternoster, in der Regel mit nicht mehr als 25 Perlen, in der Hand"s.

Verhältnismäßig selten sind religiöse figürliche Darstellungen auf den Grabdenkmälem: Das aus der Kapelle von Gröblingen bei Miltenberg stammende Grabdenkmal des Ritters und Kapellenstifters Konrad von Bickenbach (†1393), das heute im Bayerischen Nationalmuseum in München aufbewahrt wird, ist von einem kielbogigen Tympanon mit dem Wappen Konrads unter einem Christushaupt bekrönt ${ }^{96}$. Dietz Truchseß von und zu Wetzhausen $(\dagger 1488)$ erscheint auf seinem Grabmal in der Ritterkapelle zu Haßfurt in der rechten oberen Ecke Maria mit dem Kind im Wolkenkranz ${ }^{97}$.

Mehrfach sind Ritter mit dem Pilgerhut dargestellt. Das Grabdenkmal des Heinrich von Schaumberg gen. Knoch († 1501) aus dem Friedhof der Oberen Pfarre zu Bamberg zeigt jenen im Pilgergewand kniend, mit gefalteten Händen und Rosenkranz, vor einer mehrfigurigen Gregoriusmesse ${ }^{98}$. Viele Ritter sind mit dem Abzeichen der Rit-

\section{Fortsetzung Fußnote von Seite 177}

kultur, in: Adelige Sachkultur (wie Anm. 73) 277-292, hier bes. 278-287. - Neuestens zur Sepulkralplastik: Epigraphik 1988. Fachtagung für mittelalterliche und neuzeitliche Epigraphik Graz 1988, Referate und Round-Table-Gespräche, hrsg. v. Walter Koch (ÖAW.PH Denkschriften 213, Wien 1990), darin u.a. Helfried Valentinitsch, Die Grabinschriften und Grabmäler als Ausdruck sozialen Aufstiegs im Spātmittelalter und in der frühen Neuzeit, 15-26. Zu dem - im 15.Jahrhundert in den fränkischen Quellen zumeist als Patemoster bezeichneten - Rosenkranz: Gislind Ritz, Der Rosenkranz, in: 500 Jahre Rosenkranz. 1475 Köln 1975. Ausstellung des Erzbischöfl. Diözesan-Museums Köln (Köln 1975) 51-101: Hartmut Boockmann, Leben und Sterben im mittelalterlichen Göttingen. Über ein Testament des 15.Jahrhunderts, in: Göttinger Jahrbuch 31 (1983) 73-94, hier 14.

"14 DI 17 (wic Anm. 39) Nr. 5.

95 Z. B. Friedrich von Berlichingen ( $†$ 1484) in der Rothenburger Franziskanerkirche: DI 15 (wie Anm. 92) Nr. 107; Heinrich Stiebar $(\dagger 1507)$ in der Pfarrkirche zu Buttenheim, der Grablege der Familie: DI 18 (wie Anm. 39) Nr. 109; Konrad von Schaumberg († 1499) in der Marienkapelle zu Würzburg: DI 27 (wie Anm. 92) Nr. 363. - Zur Kurz- bzw. Langform: Ritz, Der Rosenkranz (wie Anm.93) 65 .

${ }_{96}$ Abb. bei Reitzenstein, Rittertum (wie Anm. 2) 96; Tilmann Breuer, in: Die Parler und der schöne Stil 1350-1400. Europäische Kunst unter den Luxemburgern, Bd. 1 (Köln 1978) 350 (mit Abb.).

"7 DI 17 (wie Anm. 39) Nr.50. Wohl nach dem Vorbild des Grabmals des Dietz Truchseß von und zu Wetzhausen wurde das des Appel von Stein zum Altenstein ( $†$ 1513) gearbeitet, das sich gleichfalls in der Haßfurter Ritterkapelle befindet; neben dem knienden Ritter mit gefalteten Händen und Paternoster erscheint rechts oben ein Schmerzensmann im Wolkenkranz (Nr. 90). Von der Ikonographie her vergleichbar ist das Grabmal der Sibylle von Heideck († 1475) in der Pfarrkirche St. Johannis zu Heideck; Sibylle kniet vor einem Schmerzensmann in Wolkenglorie: Ernst Eichhorn, Die Kunstdenkmäler von Heideck, in: Dieter Deeg (Hrsg.), Heideck. Stadt und Landschaft (Nürnberg 1971) 110-119, hier 112 mit Abb. auf Taf.4.

${ }^{88}$ Michel Hofmann, Die "Gregoriusmesse“ an der Oberen Pfarte, in: Fränkische Blätter 13 (1961) 48; auch ebd. 6 (1954) 3. - Bartholomäus Truchseß von Pommersfelden (†um 1450) ist auf dem Grabmal in der dortigen Pfarrkirche als geharnischter Ritter mit Pilgerhut dargestellt, der den Helm in der rechten Hand emporhält: DI 18 (wie Anm. 39) Nr. 56. - Der Ritter Hans von Wallenrod, Amtmann zu Schwabach (†1473), ist auf dem Grabmal in der Schwabacher 
tergesellschaften dargestellt, denen sie angehörten, so z. B. Eberhard von Grumbach $(† 1487)$ in der Pfarrkirche zu Rimpar mit dem Emblem der Gesellschaft vom Stillschweigen und weiteren Abzeichen ${ }^{99}$.

Nach Ausweis des Inventars der deutschen Tafelbilder vor Dürer in Franken ist der Fundus der hier erhalten gebliebenen gemalten Epitaphien von Rittern verschwindend gering ${ }^{100}$.

Daß die Paternoster nicht nur zu den Accessoires auf den Grabdenkmälern des Adels, vor allem der Frauen, gehörten, sondern zum Devotionaliengrundstock der reicheren Familien und zugleich zu den wichtigsten Schmuckstücken zählten, ist bekannt. Aus den Schadenslisten des Jahres 1525 läßt sich bei vielen Adelsfamilien der Besitz zumeist mehrerer, vielfach aus Korallen oder wertvollen Steinen zusammengesetzter und mit silbernen Kreuzen und „untermarcken “ ausgestatteter Paternoster nachweisen; so bei Pankraz von Egloffstein drei, Achaz von Ochs zu Gunzendorf vier, Utz von Rüsenbach zu Trunstadt zwei, Gertrud von Schaumberg, der Gemahlin des Martin von Schaumberg, zwei, Rochus von Seckendorff zu Hallerndorf zwei; Alexander Stiebar zu Rabeneck besaß vier Paternoster, davon drei mit silbernen Heiligen und einen mit einem vergoldeten St. Georg, Paulus von Plankenfels auf Wichsenstein hatte einen Paternoster mit zwei silbernen Bisamäpfeln. Derartige durchbrochen gearbeitete, mit einer Duftstoffpaste gefüllte Kugeln werden von dem Nürnberger Meistersinger Hans Folz in seinem Spruch von der Pestilenz aus dem Jahr 1482 näher beschrieben; der Füllung wurde medizinisch-magische Wirkung zugeschrieben ${ }^{101}$. Vor

\section{Fortsetzung Fußnote von Seite 178}

Pfarrkirche mit Pilgermütze dargestellt; er steht zusammen mit seiner Frau Sibylle von Lentersheim († 1454) unter einem Tympanon mit einem Erbärmdechristus: Herbert Reber, Die Stadtkirche zu Schwabach (Kirchenführer) (Schwabach 1965) 12 (mit Abb.); Georg Stolz, Stadtkirche St. Martin Schwabach (Große Baudenkmäler 349, München/Berlin 1983) 10 (ohne Abb.); Bernbart Jäbnig, Johann von Wallenrode O.T. (Quellen und Studien zur Geschichte des Deutschen Ordens 24) 179.

99 Tilman Riemenschneider - Frühe Werke. Kat. der Würzburger Ausstellung (Berlin 1981) 337-340 (Bodo Buczinski, Artur Kratz). - Weitere Beispiele: Albrecht Stiebar d.A. († 1491), brandenburg-ansbachischer Amtmann zu Cadolzburg, in der Turmkapelle der Pfarrkirche zu Buttenheim mit dem Schwanenritterorden: Otto Graf Seefried, Aus dem Stiebar-Archiv. Forschungen zur Familiengeschichte von Bauer, Bürger und Edelmann in Ober- und Mittelfranken (Freie Schriftenfolge der Gesellschaft für Familienforschung in Franken 4, Nürnberg 1953) Tafel V; DI 18 (wie Anm. 39) Nr. 75; Philipp Fuchs von und zu Schweinshaupten († 1494) in der Pfarrkirche zu Schweinshaupten mit dem Spangenorden: D 17 (wie Anm.39) Nr.53; Martin von Seinsheim ( $\dagger 1434)$ in der Würzburger Marienkapelle mit dem Fürspängerorden: DI 27 (wie Anm. 92) Nr. 209; Friedrich von Seinsheim († 1409) in der Dominikanerinnenklosterkirche zu Rothenburg o. d. Tauber mit Fürspängerorden: DI 15 (wie Anm. 92) Nr. $43+$.

${ }_{100}$ Genannt sei nur das Epitaph des Heinrich von Rechberg ( $\left.† 1437\right)$ und seiner Gemahlin Sophie, einer geb. Gräfin von Helfenstein, im Eichstätter Dom; das Epithaph zeigt Christus am Kreuz zwischen Maria und Johannes mit vier das Blut Christi auffangenden Engeln, zu Füßen des Kreuzes das kniende Stifterpaar: Alfred Stange, Kritisches Verzeichnis der deutschen Tafelbilder vor Dürer, III. Bd.: Franken (wie Anm. 52) Nr. 343.

101 StAB, Rep. 48, Nr.6, Prod.7, 10; 29,1; 37,7; 2; Nr.7, Prod. 38,11; 42, 6 u. 4; 43,2; 49,3. Endres, Adelige Lebensformen in Franken zur Zeit des Bauernkrieges (wie Anm.73) 27; Goez, Das Leben (wie Anm. 73) 25. - Ritz, Der Rosenkranz (wie Anm. 93) 67, zitiert das gereimte Pest- 
den verlorenen Halsbändern wird von Alexander Stiebar zu Rabeneck ein vergoldetes Kreuz im Gewicht von fünf Lot und im Wert von 1 Gulden aufgeführt ${ }^{102}$.

Singulār ist das Grabdenkmal des Ritters Arnold von Uissigheim, der - nachdem er 1332 wegen Straßenraubes des Wertheimer Territoriums verwiesen worden war - sich als König Armleder an die Spitze einer von bāuerlichen und städtischen Unterschichten, darunter aus Tauberbischofsheim, Mergentheim, Iphofen und Kitzingen, getragenen Aufstandsbewegung setzte, die ein Blutbad in zahlreichen Judengemeinden Frankens anrichtete. Seine Scharen wurden mit Hilfe der Würzburger Stadtbevölkerung bei Ochsenfurt geschlagen, Arnold von Uissigheim in Kitzingen hingerichtet. Auf dem ursprünglich in der Mitte des Chores der Uissigheimer Pfarrkirche befindlichen Hochgrab, dessen Deckplatte in beschädigter Form erhalten ist, ist der Ritter mit gefesselten, in Armleder gehüllten Unterarmen dargestellt. Auf seinem Hals liegt ein Schwert auf, das auf seinen Tod hinweist. Die (ergānzte) Umschrift der Platte lautet: "† ANNO DOMINI MCCCXXXVI SUBIIT GLADIO BEATUS ARNOLDUS IUVENIS MILES DE VSSINKEM XVIII. KL. DECEMBRIS.“103

In der Volksüberlieferung wurde Arnold von Uissigheim früh als seliger Ritter, der von Juden überfallen und getötet worden sein soll, angesehen und mit dem Epitheton „beatus“ versehen. Schon bald berichteten die Quellen von Wundern an seinem Grab. Bis in das 18. Jahrhundert wurde das Grab von Wallfahrern aus Fulda nach Walldürn aufgesucht. Zu Ende des 17. Jahrhunderts wurde der Grabstein von dem in der Regel dem Stifter einer Kirche vorbehaltenen bevorzugten Platz in der Mitte der Kirche auf die Epistelseite versetzt, möglicherweise weil die dem bestatteten Ritter erwiesene Hochschätzung von den für die Kirche Verantwortlichen auf diese Weise zurückgedrāngt werden sollte ${ }^{104}$. Klaus Arnold wies auf die in der Armlederbewegung wirksamen religiösen Motive hin: Wie bereits als Randerscheinung der Kreuzzüge in das Heilige Land, erschien den Zeitgenossen des fränkischen Königs Armleder das Vorgehen gegen die Juden als ein neuer Kreuzzug ${ }^{105}$.

\footnotetext{
Fortsetzung Fußnote ton Seite 179

regimen des Nürnberger Meistersingers und Spruchdichters Hans Folz aus dem Jahr 1482: „ein pisem apfel mag man dragen - gemacht als die recept das sagen - von weirach aloe ambra kamphar negelin been asa - muscus macis corticum citri - pulvis mente nucis musstati - calami aromatici - ozimi valeriani - rosem mastix sandalum - cubeben cinamomum - zytwar buglossa laudanum - mai oranum und spodium - hievon man zweyrley öpfel macht - nach sumers und nach winters acht." Zu Hans Folz und seinen Pestregimina: Jobannes Janotc, H. F., in: Verfasserlexikon" ${ }^{2}$, Bd. 2 (Berlin/New York 1980) 769-793, hier 771, 789-791.

102 StAB, Rep. 48, Nr.7, Prod. 43,2.

103 DI 1 (wie Anm. 92) Nr.109; Klaus Arnold, Die Armledererhebung in Franken 1336, in: Mainfränkisches Jahrbuch 26 (1974) 35-62, hier 51.

104 Arnold, Die Armledererhebung (wie vorige Anm.) $52 \mathrm{f}$.

105 Ebd. 57.
} 
VI.

Allgemein hielten die Grabdenkmäler mit den gerüsteten Rittem und darüber angebrachten Totenschilden bei den Betrachtern über die Zeiten hinweg Gedanken an die militia Christi wach und trugen als einprägsame steinerne Vorbilder auf ihre Weise nicht unwesentlich dazu bei, daß sich viele bereits in der Zeit der Kreuzzüge ausgebildete Frömmigkeitsvorstellungen im Adel selbst, aber auch weit über den Adel hinaus erhielten.

Auch die schon von ihrer Entstehung mit dem Gedanken der militia Cbristi eng verbundene Idee der Pilgerfahrten blieb im spāten Mittelalter unter den Adligen stets lebendig. Herkömmliche Motivationen wurden gelegentlich mit außergewöhnlichen Aktionen verbunden. 1316 begaben sich der Ritter Heinrich von Herbelstadt und seine Brüder Wilhelm und Rudolf nach dem Tod ihres Vaters Volknand von Herbelstadt um des Seelenheiles ihres Vaters willen auf Pilgerreise und entließen aus dem gleichen Grund zwei Eigenleute und deren Nachkommen in die Freiheit ${ }^{106}$.

Der Ritter Albrecht von Aufseß, der 1356 der von ihm als Begräbnisplatz bestimmten Kirche zu Aufseß sein Pferd und seine Waffen sowie eine jährliche Seelenmesse zu seinem eigenen Gedächtnis stiftete, ließ zur Erinnerung an seine Pilgerfahrt in das Heilige Land auf seinem Grabstein das Jerusalemkreuz anbringen ${ }^{107}$.

Im 15.Jahrhundert setzte eine neue Blütezeit der Pilgerfahrten des Adels ein. Die Nachrichten über Pilgerreisen ihrer Vorfahren wurden in vielen Familien gewissenhaft gesammelt. In der Eybschen Familie ist die Teilnahme an Fahrten in das Heilige Land für mehrere Mitglieder überliefert: 1350 von Ludwig von Eyb als Begleiter Herzog Ottos von der Pfalz, 1435 von Konrad von Eyb als Begleiter der Markgrafen Albrecht und Johann von Brandenburg, 1468 von Anselm von Eyb als Begleiter Graf Eberhards III. von Württemberg und 1476 von Ludwig von Eyb d. J. als Begleiter Herzog Albrechts von Sachsen. Úber die beiden letzten Pilgerfahrten haben die Herren von Eyb Reiseberichte hinterlassen ${ }^{108}$. Für Konrad von Schaumberg, den Hofmarschall der Würzburger Bischöfe, der 1499 ,an der widerfart von dem heilgen grab uff dem mere" verstorben war, ließ der Würzburger Rat dem letzten Willen des Verstorbenen entsprechend „ein stein und wappen“ in der Würzburger Marienkapelle setzen. Das

106 Nachlaß Marschalk von Ostheim. Urkunden, bearb. v. Rudolf M. Kloos (Bayerische Archivinventare 38, Neustadt a. d. Aisch 1974) Nr. U 436.

107 StAB, Rep. 205/I L. 703 Nr.157; Hellmut Kunstmann, Die Burgen der westlichen und nördlichen Fränkischen Schweiz, T.2 (VGFG IX/28,2, Würzburg 1972) 100.

108 Reitzenstein, Rittertum (wie Anm. 2) 103; Eyb, Das reichsritterliche Geschlecht (wie Anm. 53) $51 \mathrm{f} ., 78$; Helgard Ulmschneider, Anselm von Eyb, in: Verfasserlexikon ${ }^{2}$, Bd. 1 (Berlin/New York 1977/78) 381-382; dies., Ludwig von Eyb d. J. zum Hartenstein, ebd. Bd. 5, 1006-1015. Anselm und Ludwig von Eyb d. J. wurden in Jenusalem zu Rittern vom Heiligen Grab geschlagen. Allgemein: Ludwig Schmugge, Die Pilger, in: Unterwegssein im Spätmittelalter, hrsg. v. Peter Moraw (ZHF Beiheft 1, Berlin 1985) 17-47. - Ingrid Matschinegg, Albert Müller, Migration - Wanderung - Mobilitāt in Spätmittelalter und Frühneuzeit. Eine Auswahlbibliographie (Medium aevum quotidianum 21, Krems 1990). 
von Tilman Riemenschneider geschaffene Grabdenkmal zeigt den Ritter entgegen zeitgemäßem Brauch helmlos mit dem Paternoster in der Rechten ${ }^{109}$.

Im Zusammenhang mit der neuen Heilig-Land-Begeisterung erfuhr in ritterlichen Kreisen Frankens auch die Heilig-Grab-Frömmigkeit einen neuen Aufschwung. Der eng mit dem Benediktinerkloster auf dem Michelsberg bei Bamberg verbundene Heinrich Marschalk von Rauheneck ließ etwa zwischen 1495 und 1503 den Kreuzweg von der Spitalkirche St. Elisabeth im Sand zur Michelsberger Propstei St. Getreu sowie das dortige Heilige Grab errichten, wenige Jahre später auch den benühmten Kreuzweg des Adam Kraft vom Pilatushaus unter der Nürnberger Burg zum Johannisfriedhof mit dem Heiligen Grab in der von ihm erneuerten Holzschuher-Kapelle. Für die Spitalkirche St. Elisabeth zu Bamberg und die Propsteikirche St. Getreu stiftete Heinrich Marschalk von Rauheneck zudem Messen zum Gedächtnis an den Kreuzweg Christi ${ }^{10}$. Der Bamberger Kreuzweg gilt als der älteste vollständig erhaltene in Deutschland ${ }^{111}$.

Weit verbreitet waren im Adel Pilgerfahrten nach Rom und zu den anderen großen Pilgerstätten der Christenheit sowie Heiltumsfahrten zu den Weisungen in und außerhalb des Reiches. Ziel vieler Pilgerfahrten war die Erlangung des Ritterschlags an einem Gnadenort. 1431 begleitete Peter von Brunn, Mitglied einer damals in Münnerstadt ansāssigen Adelsfamilie, mit dieser Absicht Landgraf Ludwig I. von Hessen nach St. Josse bei Montreuil in Westflandern ${ }^{12}$. Anläßlich einer Romfahrt zum Gewinn möglichst zahlreicher Ablässe für sich und seine Familie stellte Ludwig von Eyb d. Ä. 1475 eine heute in Neustadt a. d. Aisch verwahrte Sammelhandschrift mit einschlägiger Reiseliteratur zusammen, die u.a. eine von ihm selbst eingeleitete Abschrift der Mirabilia Romae sowie die Palästina-Reiseberichte seiner Söhne Anselm und Ludwig enthält ${ }^{113}$.

Häufig belegt ist die Beteiligung fränkischer Adliger an der im 15.Jahrhundert anschwellenden Wallfahrtsbewegung sowie - zumeist in bevorzugter Funktion - an den lokalen Prozessionen. In Bamberg trugen zwei Ritter bei der großen Prozession zum Heinrichsfest den Heinrichsschrein, bei der Fronleichnamsprozession die zum Bamberger Heiltumsschatz zählenden Fähnlein des hl. Georg und des hl. Heinrich"114. Eine Reihe von Adligen - die Ritter Jörg von Thüngen, Hans Fuchs, Anton von Sek-

${ }_{109}$ DI 27 (wie Anm. 92) Nr. 363. - Nach Dieter Harmening „eines der schönsten Ritterbilder des späten Mittelalters": Fränkische Mirakelbücher. Quellen und Untersuchungen zur historischen Volkskunde und Geschichte der Volksfrömmigkeit, in: WDGB 28 (1966) 25-240, hier 99.

110 Renate Baumgärtel-Fleischmann, Bamberger Plastik von 1470 bis 1520, in: BHVB 104 (1968) 7-352, hier 71-75, 339-341.

11 Ebd. 75.

112 Wilbelm Engel, Die fränkischen Geschlechter von Brunn um 1400, in: Mainfränkisches Jahrbuch 3 (1951) 106-126, hier 116. - Heiltumsfahrten des Adam und Albrecht Schenk von Schenkenstein nach Nümberg zu den Weisungen 1448 und 1449: Gerbard Rechter, Das Verhältnis der Reichsstädte Windsheim und Rothenburg ob der Tauber zum niederen Adel ihrer Umgebung im Spätmittelalter, in: JFLF 41 (1981) 45-87, hier 67, 81.

113 Helgard Ulmschneider, Ludwig von Eyb d. A. zu Eybburg, in: Verfasserlexikon², Bd. 5, 9971006, hier 999.

114 Xaver Haimerl, Das Prozessionswesen des Bistums Bamberg im Mittelalter (Münchener Studien zur historischen Theologie 14, München 1937) 40, 70. 
kendorff, Wigelas von Wolfskeel und der Schultheiß Christoph Fuchs - waren an der Entstehung der Heilig Blut-Wallfahrt in der zu Ebrach gehörenden Pfarrei Burgwindheim im Jahr 1465 maßgeblich beteiligt. Die beiden zuerst genannten Ritter hatten bei der Fronleichnamsprozession um das Dorf den Priester mit der Monstranz begleitet und bezeugten zusammen mit den drei anderen das während der Prozession geschehene Hostienwunder, das schließlich auf Initiative der Ebracher Zisterzienser zur Heilig-Blut-Wallfahrt führte. Hauptstifter der ersten Wallfahrtskapelle war Konrad von Thanhausen; 1467 wurde die Kapelle zu Ehren des Fronleichnams Christi, des Heiligen Kreuzes, Marias und einer Reihe von Heiligen geweiht ${ }^{115}$. Auch an der Wallfahrt des Jahres 1476 nach Niklashausen waren mehrere fränkische Ritter beteiligt ${ }^{116}$.

Die Idee der militia Christi wurde in der Teilnahme am Kampf des Deutschen Ordens gegen Polen-Litauen oder an den Zügen gegen die Franken unmittelbar bedrohenden Hussiten konkret neu belebt. Erkinger von Seinsheim, der um das Jahr 1400 in Polen kämpfte, stiftete im Zisterzienserkloster Byszow an der Weichsel eine Seelmesse für seine gefallenen Kameraden ${ }^{117}$. Auch an der Schlacht von Tannenberg nahm ein Kontingent frānkischer Ritter teil ${ }^{118} .1427$ suchten vor dem Feldzug gegen die Hussiten fränkische Ritter die dem hl. Mauritius geweihte Kapelle der wahrscheinlich hennebergischen Burg Bergheide beim Reichsdorf Gochsheim im Gebet auf; die abgegangene Kapelle war zu jener Zeit eine bevorzugte Pilgerstätte des ritterlichen Adels aus dem Schweinfurter Umland ${ }^{119}$.

\section{VII.}

Religiöse Literatur lâßt sich bisher nur in geringem Umfang im Besitz fränkischer Adliger nachweisen. Die vor über hundert Jahren von Albin Czerny für Oberösterreich getroffenen Aussagen über den Bücherbesitz eines Landadligen um 1500 dürften, wie die Durchsicht der Schadenslisten aus dem Bauernkrieg von 1525 zeigt, den Verhältnissen in anderen Landschaften, wohl auch in Franken, weitgehend entsprochen haben. Czerny zählte zum Grundstock der Bibliothek eines Landherrn u.a. eine Bibel, einen deutschen Psalter, ein deutsches Evangelien- und Epistelbuch, weiter Sammlun-

\footnotetext{
113 Harmening, Fränkische Mirakelbücher (wie Anm. 109) 39; Bruno Neundorfer, Burgwindheim und seine Wallfahrt. Zum 500jāhrigen Jubilāum des eucharistischen Gnadenortes im Steigerwald 1465-1965 (Bamberg 1965) 12-16; Klaus Guth, Das Entstehen fränkischer Wallfahrten. Zur Phänomenologie, Typologie und Aitiologie der Wallfahrtsgenese, in: Mainfränkisches Jahrbuch 29 (1977) 39-53.

116 Klaws Arnold, Niklashausen 1476. Quellen und Untersuchungen zur sozialreligiösen Bewegung des Hans Behem und zur Agrarstruktur eines spätmittelalterlichen Dorfes (Saecula spiritalia 3, Baden-Baden 1980) 71-74.

117 Gerbard Rechter, Die Herrschaft Schwarzenberg in Mittelfranken, in: JbMfr. 92 (1984/85) 109-121, hier 113.

118 Andrian-Werburg, Das Totenbuch (wie Anm. 55) Nr.197: „Memoria domini Conradi de Lichtenstein, magni commedatoris [!] in Prußia, qui obii [!] in bello anno domini 1410, cuius altare est sancte Katherine, et hec arma." Ders., Nekrolog des Franziskanerklosters Coburg, in: 800 Jahre Deutscher Orden (wie Anm.21) Nr.II.8.5.
}

119 Zimmermann, Patrozinienwahl (wie Anm. 24) Bd. 21, 46. 
gen deutscher Predigten, erbauliche Traktate und Gebetbücher ${ }^{120}$. In den Schadenslisten wird - abgesehen von den bereits genannten Meßbüchern - bei etwa zwanzig Geschädigten der Besitz von Büchern, darunter offenbar mehrfach von Druckwerken, deklariert, in mehreren Fällen nur pauschal. In dem hier interessierenden Zusammenhang lassen sich folgende Beispiele nennen: Balthasar von Egloffstein gibt unter den Verlusten ein Evangelienbuch und ein Legendenbuch an, Peter von Redwitz zu Theisenort einen Auszug aus der Bibel, Hans von Schaumberg zum Rod ein Neues Testament, Gabriel von Streitberg zu Grub eine deutsche Bibel des Alten und Neuen Testaments sowie ein Passional der Heiligenleben, Moritz von Wiesenthau zu Wachenroth ein Passional ${ }^{121}$. Der für den Humanismus aufgeschlossene Hieronymus Schenk von Siemau trat selbst als Dichter und Theologe hervor. Als begeisterter Marienverehrer veröffentlichte er 1503 eine poetische Verherrlichung der Unbefleckten Empfãngnis. Aus dem Jahr 1504 stammen seine deutsche Umdichtung des Salve Regina und eine seiner Mutter Walburga in Coburg gewidmete Epistel über die Anfechtungen in dieser Welt. Zehn Jahre später erschien von ihm eine lateinische Erklärung des 144. Psalms ${ }^{122}$.

\section{VIII.}

Bedeutung gewannen im Lauf des 14. und 15.Jahrhunderts die Rittergesellschaften, die ihre Mitglieder zu gegenseitigem Beistand bei Angriffen von außen verpflichteten, teilweise weit in das persönliche Leben eingreifende ethisch-moralische Forderungen an jene stellten und sie zu bestimmten, regelmäßig zu verrichtenden Gebeten verpflichteten. Im Gegensatz zu den hierarchisch gegliederten geistlichen Ritterorden betonten die Rittergesellschaften die Gleichheit ihrer Mitglieder. Sie ließen zum Teil, wenn auch in beschränkter Zahl, Damen zu ${ }^{123}$. Alle im folgenden genannten Gesellschaften in Franken waren dem besonderen Schutz Marias unterstellt.

Die älteste Rittergesellschaft in Franken von überregionaler Bedeutung war die der Fürspänger, benannt nach ihrem Abzeichen, einer goldenen Gürtelspange als Abbild der Gürtelspange der Jungfrau Maria'24. Die Gründung der Gesellschaft erfolgte der Tradition nach 1352 oder 1355 durch Karl IV. in Nürnberg; 1375 wird als Gründungsjahr für den Würzburger Zweig der Fürspänger-Gesellschaft, 1392 für den Bamberger Zweig angegeben. Spätestens zu Beginn des 15.Jahrhunderts hatte die Gesell-

120 Albin Czerny, Die Bibliothek des Chorherrenstiftes St. Florian (Linz 1874) $54 \mathrm{ff}$. Otto Brunner; Österreichische Adelsbibliotheken des 15. bis 18. Jahrhunderts als geistesgeschichtliche Quellen, in: ders., Neue Wege der Verfassungs- und Sozialgeschichte (Göttingen ${ }^{2} 1968$ ) 281-293; Pletichal. Adel und Buch (wie Anm. 73) 21.

${ }_{121}$ StAB, Rep. 48, Nr.6, Prod. 7,1 u. 2; 32, 21; Nr.7, Prod. 38,4; 44,9; 51,5. Pleticha. Adel und Buch (wie Anm. 73) 24.

122 Michel Hofmann. Hieronymus Schenk v. Siemau. Ein vergessener fränkischer Dichter, in: Fränkische Blätter $2(1950) 88$.

123 Zusammenfassend: Bernhard Heydenreich, Ritterorden und Rittergesellschaften. Ihre Entwicklung vom spāten Mittelalter bis zur Neuzeit. Ein Beitrag zur Phaleristik (Würzburg 1960).

${ }^{124}$ Paul Ganz, Die Abzeichen der Ritterorden, in: Archives héraldiques Suisses. Schweizerisches Archiv für Heraldik 20 (1906) 16-25, hier $23 \mathrm{f}$. 
schaft ihren Sitz an den drei bedeutendsten Marienkirchen Frankens: an den Marienkapellen zu Nürnberg und Würzburg sowie an der Oberen Pfarrkirche zu Bamberg. 1408 bzw. 1412 wurden die in Bamberg und Würzburg errichteten Vikarien durch die zustāndigen Bischöfe bestātigt. Zu Trauergottesdiensten und Jahrtagen fanden sich die Mitglieder jeweils am Sitz ihres Zweiges zusammen ${ }^{125}$.

Die Rittergesellschaft zu Unserer Lieben Frau, der spätere Schwanenorden, wurde 1440 durch Kurfürst Friedrich von Brandenburg bei der Marienkirche des Prämonstratenserstifts auf dem Harlunger Berg bei Altbrandenburg für ursprünglich dreißig Mānner und sieben Frauen gegründet. Das Kleinod bestand aus einem Marienbild mit darunter anhāngendem, mit einem Handtuch mit zumeist zehn Fransen umwundenen Schwan. Die Beschrānkung der Mitgliederzahl wurde schon 1443 aufgehoben. Úberwogen in den ersten Jahren die märkischen Ritter, so nahm unter dem wachsenden Einfluß von Markgraf Albrecht Achilles die Zahl der fränkischen Ritter in der Gesellschaft stāndig zu. 1459 stiftete Albrecht Achilles für die südlich des Thüringer Waldes sitzenden Mitglieder eine Maria und dem hl. Georg geweihte eigene Kapelle in der Stiftskirche St. Gumbert zu Ansbach und erwirkte für diese 1460 die gleichen Privilegien, wie sie die Marienkirche auf dem Harlunger Berg besaß. 1484 wurde der fränkische Zweig der Gesellschaft als selbständige Korporation errichtet ${ }^{126}$.

Die Statuten der Gesellschaft verlangten von den Mitgliedern einen untadeligen Lebenswandel. Beim Eintritt war ein festgesetzter Beitrag zu entrichten. Als Gebetspensum waren ursprünglich sieben Pater noster und sieben Ave Maria täglich vorgesehen, der Druck der Statuten aus der Zeit um 1515 enthält folgendes spezielles Mariengebet:

„O mutter aller seligkait, dich lobt die Christenhait,

bey pflichten zu allen stunden, dich in sollicher innigkait

zu deines kindes lobes wirdigkait, hab ich mich verpunden,

125 Karl H. Roth von Schreckenstein, Geschichte der ehemaligen freien Reichsritterschaft in Schwaben, Franken und am Rheinstrome, Bd. 1, Freiburg 1859; Seefried, Aus dem Stiebar-Archiv (wie Anm. 99) 13-16; Heydenreich (wie Anm. 123) 33, 38, 55 f.; Urkundenbuch der Marienkapelle am Markt zu Würzburg 1317-1530, hrsg. v. Alfred Wendeborst (Quellen und Forschungen zur Geschichte des Bistums und Hochstifts Würzburg 27, Würzburg 1974) 20f., 24 f.; Franz Machilek, Privatfrömmigkeit und Staatsfrömmigkeit, in: Kaiser Karl IV. Staatsmann und Mãzen, hrsg. v. Ferdinand Seibt (München 1978) 87-101, hier 100; Jobannes Müllner, Die Annalen der Reichsstadt Nürnberg von 1623, Teil II: Von 1351-1469, hrsg. v. Gerbard Hirschmann (Quellen zur Geschichte und Kultur der Stadt Nürnberg 11/II, Nürnberg 1984) 13-16; Werner Scharrer, Die Laienbruderschaften in der Stadt Bamberg vom Mittelalter bis zum Ende des Alten Reiches. Geschichte - Brauchtum - Kultobjekte, in: BHVB 126 (1990) 21-392, hier 78-81. - Frau Dr. Marie Studničková, Prag, bereitet eine Untersuchung zu den Hoforden der Luxemburger vor; sie hat darüber auf einem Internationalen Colloquium in Prag aus Anlaß der Ausstellung „Illuminierte Handschriften der Hussitenzeit“ (Prag, 30. Januar - 1. Februar 1991) kurz berichtet.

126 S/iegfried] Haenle, Urkunden und Nachweise zur Geschichte des Schwanen-Ordens, in: Jahresberichte des historischen Vereins für Mittelfranken 39 (1873/74) 1-178; Theodor Däschlein, Der Schwanenorden und die sogenannte Schwanenordens-Ritter-Kapelle in Ansbach, ebd. 63 (1919-1926, ersch. 1927) 1-124; Heydenreich, Ritterorden (wie Am. 123) 41 f., 45 f., 48f. u. ö.; Günther Schubmann, Die Markgrafen von Brandenburg-Ansbach. Eine Bilddokumentation zur Geschichte der Hohenzollern in Franken (JbMfr. 90, Ansbach 1980) 401-413. 
on sorg ich nit enpin, das hertz mut syn sein gar klain das bedencken thut, wo wenn und zu welcher stundt, gedancken werck und mut, mich an deinem lob krencken. $O$ rayne junckfraw so ist not, das dein gute ubung groß mir solche gnad geb, das mir rew beich und bueß, ich premse meinen mut, so ich in hulden leb. In sunderhayt so pit ich dich, gib solche gnad mir, das ich in meinen jarn in rechtem edeln standt, on schandt und on missethat, mit eren mag farn, an der letzten stundt, wenn ich leyd schmertzen unnd pein, und von hinnen verschayd, do mich dann Maria trost, das ich sicherlich gantz erlost, far hin in deinem glait Maria mich in das himelreich belaid. Amen. ${ }^{{ }^{127}}$

Die Marienfeste sollen von den Mitgliedern mit Gottesdienstbesuchen besonders gefeiert werden ${ }^{128}$.

Das Abzeichen der Gesellschaft wurde in den Statuten auf ihre religiös-ethischen Ziele hin gedeutet: die Strahlenkranzmadonna über der Mondsichel als Zeichen der durch Maria empfangenen Gnaden, der Schwan zunāchst als Erinnerung an den Tod (1443), später auch als Zeichen der Freiheit, die Fransen an die Einhaltung der Zehn Gebote. Das Totengedāchtnis wurde eingehend geregelt. An die toten Mitglieder sollten die Totenschilde in der Kaplle der Gesellschaft im Gumbertusstift zu Ansbach erinnern $^{129}$.

Zur Ehre Gottes, Marias und aller Heiligen, insbesondere der Vierzehn Nothelfer und des hl. Christophorus gründete noch vor $1470 \mathrm{Graf}$ Wilhelm von Henneberg an der Prämonstratenserstiftskirche zu Veßra, wo sich das Erbbegräbnis der Familie befand, eine Gesellschaft, die Papst Sixtus IV. 1480 bestātigte, und deren Mitglieder sich verpflichteten, täglich ein Vaterunser und ein Ave Maria zu beten. Auch Frauen konnten in die Gesellschaft aufgenommen werden. Männer hatten beim Eintritt vier Gulden zu bezahlen, Frauen, deren Männer bereits Mitglieder waren, einen Gulden, sonst gleichfalls vier Gulden. Die Gelder nahm der Abt von Veßra „zur Stärkung der Gottesdienste“ ein. Das Abzeichen der Gesellschaft bestand aus einer Gliederkette aus 14 geflügelten Engeln, auf deren Brust der Heilige Geist dargestellt und jeweils der Name eines Nothelfers eingraviert war. Das anhängende Medaillon trug eine Christophorusdarstellung; an dem Medaillon hingen acht Kettchen mit „Klötzlein [...] zu Bedeutung der 8 Seeligkeiten“. Die Kette mußte an bestimmten Festtagen von den Mitglie-

127 Statutenbüchlein des Schwanenritterordens (Druck: Nürnberg, Hieronymus Hölzel, um 1515): Staatsarchiv Nürnberg, Fürstentum Brandenburg-Ansbach, Stift St. Gumbert, Urkunden, Nr. 555. Faksimile (mit Nachwort von Günther Scbubmann, Neustadt a. d. Aisch 1987) fol.8.

128 Ebd. fol. 1vff.

129 Reitzenstein, Rittertum (wie Anm. 2) 102 f.; Däschlein, Der Schwanenorden (wie Anm. 126) 88-93. - Hans Folz griff um 1480 das Thema der Totenschilde und Wappen in seiner Rede „Der Arme und der Reiche" kritisch auf: Janota, Hans Folz (wie Anm. 101) 785. 
dern getragen werden; bei Unterlassung betrug die Strafe vier Pfennige, die an die Armen fielen ${ }^{130}$.

In dem seit 1463 errichteten Kreuzgang des nahezu ausschließlich mit adligen Nonnen besetzten Zisterzienserinnenklosters Himmelkron ließ die Äbtissin Elisabeth von Künßberg im Gewölbe des östlichen Eckjochs um das Wappen ihrer Familie Stuckreliefs von zwölf Herolden mit Abzeichen deutscher und ausländischer Rittergesellschaften anbringen. Nach Joachim Hotz lassen sich keine unmittelbaren Bezüge zum Kloster nachweisen. Offenbar ging es der Auftraggeberin darum, die Verbundenheit des Konvents mit den Zielen der Rittergesellschaften zum Ausdruck zu bringen $^{131}$.

Zu den frühesten Zusammenschlüssen adliger Damen im Reich gehörte die Schwesternschaft von der Agelblume, die 1380 von 31 fränkischen adligen Frauen zu Königsberg in den fränkischen Ortlanden gegründet wurde. Ihr Abzeichen bestand in einer silbernen, vergoldeten Akelei. Úber der weltlichen Kleidung trugen die Damen einen Ledergürtel, darunter ein Skapulier. Während der Feier der Jahrtage und bei Zusammenkünften bewohnten die Frauen ein Haus, das mehrere Zellen enthielt. Ledige Frauen mußten beim Eintritt mindestens vierzig Jahre alt sein; verheiratete durften nur mit Erlaubnis des Ehemanns eintreten. Neben dem täglichen Gebet und dem vorgeschriebenen Fasten widmeten sich die Schwestern Aufgaben in der Armen- und Krankenpflege. 1436 erlangte die Schwesternschaft Ablāsse und Privilegien durch das Basler Konzil. Die Leitung der Schwesternschaft oblag einer Königin. 1489 zählte die Schwesternschaft unter der damaligen Königin Elisabeth Fuchs von Thüngen 23 Mitglieder. 1517 folgte ihr als letzte Königin Margareta Steinruckin von Altenstein. Aus dem gleichen Jahr liegt ein Druck der Statuten vor. Als Königsberg 1524 evangelisch wurde, löste sich die Schwesternschaft auf ${ }^{132}$.

Zahlreiche Mitglieder des fränkischen Adels schlossen sich außer einer oder mehreren Rittergesellschaften auch den allenthalben an bedeutenderen Kirchen bestehenden Bruderschaften $a^{133}$. Auffallend hoch ist die Zahl adliger Mitglieder in vielen klösterlichen Bruderschaften und Priesterbruderschaften wie in der um 1400 entstan-

130 Sigmund Frbr. v. Pölnitx, Vierzehnheiligen. Eine Wallfahrt in Franken (Weißenhorn 1971) 38; Josef Leinweber, Das Hochstift Fulda vor der Reformation (Quellen und Abhandlungen zur Geschichte der Abtei und Diözese Fulda 22, Fulda 1972) $260 \mathrm{f}$.

131 Heydenreich, Ritterorden (wie Anm. 123) 56-58, 112-115; Joachim Hotz, Zisterzienserklöster in Oberfranken. Ebrach - Langheim - Sonnefeld - Himmelkron - Schlüsselau (Große Kunstführer 98, München/Zürich 1982) 75 (Abb.), 78.

132 Norbert Backmund, Die kleineren Orden in Bayem (wie Anm. 35) $21 \mathrm{f}$.: Schwestern von der Agelblume, Aglai-Schwestern. Hier auch zum Statutendruck.

133 Robert Ebner, Das Bruderschaftswesen im alten Bistum Würzburg. Eine Untersuchung unter besonderer Berücksichtigung der geistlichen Bruderschaften der Stadt Kitzingen (Forschungen zur frānkischen Kirchen- und Theologiegeschichte, Würzburg 1978) mit zahlreichen Einzelbelegen. 
denen Liebfrauenbruderschaft beim Bamberger Karmelitenkloster ${ }^{134}$ oder der zwischen 1380 und 1390 entstandenen Priesterbruderschaft an der Baunach ${ }^{135}$.

Noch unzureichend geklärt sind die mit der Marienkapelle zu Haßfurt zusammenhängenden Fragen; sie wird bereits seit dem 17. Jahrhundert als Ritterkapelle bezeichnet $^{136} .1413$ wurde eine dort bestehende Marienbruderschaft für Priester und Laien durch den Würzburger Bischof Johann von Brunn bestātigt. Nach Ausweis der durch den Jesuiten Johannes Gamans gesammelten Nachrichten gehörten der Bruderschaft von Anfang an zahlreiche Mitglieder des Adels an, darunter auch Frauen, zum Teil aus weit entfernten Orten. An der Entstehung der Bruderschaft war der zeitweilige Haßfurter Pfarrer Dr. Johannes Ambundi, zuvor Professor an der Würzburger Universität, sowie der Ritter Fuchs von Wallberg maßgeblich beteiligt ${ }^{137}$. Zum Bau des in der ersten Hälfte des 15.Jahrhunderts errichteten Langhauses und des 1465 geweihten Chores der Marienkapelle steuerten die Mitglieder der Bruderschaft betrāchtliche Mittel bei. Ob die 248 Wappen des außen am Chor umlaufenden Wappenfrieses jene der Bruderschaftsmitglieder oder, wie angenommen wurde, der Stifter darstellen, ist quellenmäßig nicht zu klären ${ }^{138}$. Josef Dünninger sprach von den Wappen als „Urkunden frommer Verehrung und Stiftungseifers zugleich"1 ${ }^{39}$.

Im Lauf des 15. Jahrhunderts wurde die Haßfurter Marienkapelle zur bevorzugten Grablege für den Adel der Nachbarschaft. Das Tympanon des Hauptportals mit einer Anbetung der Heiligen Drei Könige und einem langen Reiterzug empfing die zur Kapelle pilgernden Adligen in einer sie in besonderer Weise ansprechenden Form ${ }^{140}$. Bereits seit Ausgang des 14.Jahrhunderts war Haßfurt der Mittelpunkt stāndischer Einigungsbestrebungen des ritterlichen Adels des Umlandes, der 1422 erstmals als Ritterkanton Baunach auftrat ${ }^{141}$.

Rund hundert Jahre später schloß 1523 in Schweinfurt, somit in nicht allzu großer Entfernung von Haßfurt, die früh sehr weitgehend evangelisch gesinnte fränkische Ritterschaft ein gegen den Würzburger Bischof und den Schwäbischen Bund gerichtetes Bündnis. Die Versammelten scheinen die Umwandlung des Hochstifts Würzburg

\footnotetext{
134 Klaus Frbr. $:$ : Andrian-Werburg, Ein Bruderschaftsverzeichnis der Bamberger Karmeliten, in: WDGB 42 (1980) 201-213.

${ }^{135}$ Helmut Holzapfel, Die Priesterbruderschaft an der Baunach (Bayrisch-fränkische Bruderschaftsbücher des Mittelalters $2=$ EKGB 25, Nürnberg 1953) 11, 30 f., 80-84 u.ö.

136 Otto Frbr. v. Schaumberg, Die Ritterkapelle als Werk einer adeligen Marienbruderschaft. Wer baute und schmückte den Chor der Kapelle in Haßfurt? in: Fränkische Blätter 2 (1950) 86-87; Heydenreich, Ritterorden (wie Anm. 123) 33; Josef Dünninger: Die Marianischen Wallfahrten der Diözese Würzburg (Würzburg 1960) 62-67, 162 f.; Ernst Schubert. Die Landstānde des Hochstifts Würzburg (VGFG IX/23, Würzburg 1967) $63 \mathrm{f}$.

137 Nikolaus Reininger, Die Marien- oder Ritterkapelle zu Haßfurt, in: AUfr 15 (1860/61) H.1, 1-42; H.2/3, 260-294; Dïnninger, Die Marianischen Wallfahrten (wie vorige Anm.) 66; Hugo Scbnell, Haßfurt am Main (Kunstführer 417, München ${ }^{3} 1981$ ) 16.

138 Schaumberg, Die Ritterkapelle (wie Anm. 136) $86 \mathrm{f}$.

139 Dïnninger, Die Marianischen Wallfahrten (wie Anm.135) 66.

140 Abb. in: Schnell, Haßfurt (wie Anm. 137) 14. - Der Würzburger Hofmeister Dr. Sebastian von Rotenhan stiftete 1522 für sich und seine Eltern einen Jahrtag in die Ritterkapelle zu Haßfurt: Rotenban, Die Rotenhan (wie Anm. 50) 229; DI 17 (wie Anm. 39) Nr. 105.

14) Schubert, Die Landstande (wie Anm. 136) 67, 88.
} 
in ein weltliches Fürstentum erwogen zu haben. Alle Klöster in Franken sollen abgetan werden und „was ire eltern in die klester geben haben, das wellen sie nemen ${ }^{\text {“142 }}$. Die in der Cronica newer Geschichten des Wilhelm Rem enthaltenen Nachrichten über den Schweinfurter Ritterkonvent und die dort von den Versammelten angestellten Überlegungen lassen die innerhalb weniger Jahre eingetretene Änderung der Frömmigkeitshaltung und kirchlichen Einstellung beim ritterlichen Adel in Franken erkennen. Der Mentalitātswandel entspricht den von Bernd Moeller und anderen Forschern vor allem für die Städte getroffenen allgemeinen Beobachtungen ${ }^{143}$. Ein abgerundetes Bild dieses Wandels im Bereich der Adelsfrömmigkeit dürfte sich allerdings erst zeichnen lassen, wenn eine größere Zahl regional ausgerichteter Forschungen zur Laienfrömmigkeit des spätmittelalterlichen Adels vorliegt.

142 Alfred Wendehorst, Das Bistum Würzburg, T. 3: Die Bischofsreihe von 1455 bis 1617 (Germania Sacra NF 13, Berlin/New York 1978) $80 \mathrm{f}$.

143 Zur Frömmigkeit um 1500: Bernd Moeller, Deutschland im Zeitalter der Reformation (Deutsche Geschichte, hrsg. v. Joachim Leuschner, Bd. 4, Göttingen ${ }^{2} 1981$ ) 37-39; ders., Frömmigkeit in Deutschland um 1500, in: ARG 56 (1965) 5-31; Volker Press, Adel, Reich und Reformation, in: Stadtbürgertum und Adel in der Reformation, hrsg. von Wolfgang Mommsen (1979) 330-383. 
